\title{
Prunus persica plant endogenous peptides PpPep1 and PpPep2 cause PTI-like transcriptome reprogramming in peach and enhance resistance to Xanthomonas arboricola pv. pruni
}

Laura Foix ${ }^{1}$, Anna Nadal ${ }^{1}$, Maja Zagorščak², Živa Ramšak², Anna Esteve-Codina ${ }^{3,4}$, Kristina Gruden $^{2}$ and Maria Pla ${ }^{\text {* }}$

\begin{abstract}
Background: Rosaceae species are economically highly relevant crops. Their cultivation systems are constrained by phytopathogens causing severe losses. Plants respond to invading pathogens through signaling mechanisms, a component of which are of them being plant elicitor peptides (Peps). Exogenous application of Peps activates defense mechanisms and reduces the symptoms of pathogen infection in various pathosystems. We have previously identified the Rosaceae Peps and showed, in an ex vivo system, that their topical application efficiently enhanced resistance to the bacterial pathogen Xanthomonas arboricola pv. pruni (Xap).
\end{abstract}

Results: Here we demonstrate the effectiveness of Prunus persica peptides PpPep1 and PpPep2 in protecting peach plants in vivo at nanomolar doses, with $40 \%$ reduction of the symptoms following Xap massive infection. We used deep sequencing to characterize the transcriptomic response of peach plants to preventive treatment with PpPep1 and PpPep2. The two peptides induced highly similar massive transcriptomic reprogramming in the plant. One hour, 1 day and 2 days after peptide application there were changes in expression in up to $8 \%$ of peach genes. We visualized the transcriptomics dynamics in a background knowledge network and detected the minor variations between plant responses to PpPep1 and PpPep2, which might explain their slightly different protective effects. By designing a $P$. persica Pep background knowledge network, comparison of our data and previously published immune response datasets was possible.

Conclusions: Topical application of P. persica Peps mimics the PTI natural response and protects plants against massive Xap infection. This makes them good candidates for deployment of natural, targeted and environmentalfriendly strategies to enhance resistance in Prunus species and prevent important biotic diseases.

Keywords: Plant elicitor peptide (Pep), Plant defense, Prunus, RNA sequencing, Differential network analysis, Gene set enrichment analysis

* Correspondence: maria.pla@udg.edu

${ }^{1}$ Institute for Agricultural and Food Technology, Universitat de Girona, Campus Montilivi (EPS-1), 17003 Girona, Spain

Full list of author information is available at the end of the article

C C The Author(s). 2021 Open Access This article is licensed under a Creative Commons Attribution 4.0 International License, which permits use, sharing, adaptation, distribution and reproduction in any medium or format, as long as you give appropriate credit to the original author(s) and the source, provide a link to the Creative Commons licence, and indicate if changes were made. The images or other third party material in this article are included in the article's Creative Commons licence, unless indicated otherwise in a credit line to the material. If material is not included in the article's Creative Commons licence and your intended use is not permitted by statutory regulation or exceeds the permitted use, you will need to obtain permission directly from the copyright holder. To view a copy of this licence, visit http://creativecommons.org/licenses/by/4.0/. The Creative Commons Public Domain Dedication waiver (http://creativecommons.org/publicdomain/zero/1.0/) applies to the data made available in this article, unless otherwise stated in a credit line to the data. 


\section{Background}

Endogenous peptide elicitors (Peps) are a type of DAMP (damage-associated molecular pattern) first identified in A. thaliana by Huffaker and colleagues [1]. These 20-23 amino acid long peptides mature from the C-terminal portion of their larger precursor proteins called PROPEPs and are recognized by leucine-rich repeat (LRR) receptor-like kinases known as Pep receptors (PEPRs) [2-4]. As well as bacterial flagellin or EF-Tu perception, Peps not only trigger but also amplify the innate immunity of plants against pathogens [5].

To date, a number of plant peptides have been identified as defense-related signals. Up to eight PROPEP and Pep genes have been described in A. thaliana and other Brassicaceae [1, 2], seven have been found in Zea mays, three in Oryza sativa [6,7], and between one and three in many Rosaceae, Fabaceae and Solanaceae species [3, 7-9]. We have previously identified Pep sequences from 36 economically relevant Rosaceae species, with two tribe-specific Pep types per plant, Pep1 and Pep2 (Amygdaleae) and Pep3 and Pep4 (Pyreae) [10]. Among studied species, only one or two PEPRs have been observed [3, 7, 11-13]. In the same Rosaceae species we identified two PEPRs, PEPR1a and PEPR1b, with higher homology to AtPEPR1 than AtPEPR2 [10]. Pre-treatment of $A$. thaliana, Zea mays and Prunus spp. plants with Peps significantly improves their resistance to pathogens, including bacteria and fungi, as well as to herbivores $[1,3$, $6,7,9,12]$. This resistance is triggered by activating defense responses e.g. ethylene response factors (ERFs) and pathogenesis-related (PR) genes, which were upregulated after topical application of Prunus persica Peps (PpPeps) onto Prunus spp. leaves [9].

Similarly to flg22 (N-terminal part of flagellin) recognition by FLS2 (flagellin sensing 2), upon Pep perception, PEPRs interact with the coreceptor BAK1 (Brassinosteroid Receptor-Associated Kinase-1) [12, 14, 15] to induce a typical innate immunity-like response [16]. Studies in A. thaliana indicates that Pep-PEPR complexes are internalized via clathrin-mediated endocytosis (CME) [17]. In a matter of seconds this leads to the activation of downstream defense cascades including ion fluxes across the plasma membrane, such as an increase in $\mathrm{Ca}^{2+}$ influx [18], followed by phosphorylation of mitogen-activated protein kinases via MAP kinase cascades $[19,20]$. Activation of 1-amin-cyclopropane-1carboxylate (ACS) synthase is responsible for stomatal closure $30 \mathrm{~min}$ after elicitor perception [6, 21]. Biosynthesis of defense-related molecules such as ethylene (ET), salicylic acid (SA) and jasmonic acid (JA) is enhanced, as well as new PEPRs proteins replacing internalized ones [17]. An extensive transcriptional reprogramming is activated in a matter of hours [22], and cell wall re-modelling and synthesis of antimicrobial products is triggered within days [23, 24]. Interestingly, Peps seem to have positive feedback since AtPep1 induces expression of its own precursor, so amplifying the pattern-triggered immunity (PTI) response [1, 25]. This response has been specially studied in AtPeps, as they not only play a critical role in immunity, but may also be involved in development, and other biological processes from germination to flowering and seed production [2527]. However, their specific multiple functions and tissue-linked activities are still to be determined.

Stone-fruits (peaches, nectarines, cherries and plums) are among the most important fruit crops in temperate areas with a global annual production of 46 million tonnes [28]. However, several abiotic and biotic diseases, such as bacterial spot and canker of stone-fruits caused by Xanthomonas arboricola pv. pruni (hereafter, Xap), limit the production. New insights into environmentallyfriendly disease control are needed in order to replace copper derivative bactericides and antibiotics. Our previous ex vivo assays proved that protection of $P$. persica leaves against Xap infection using PpPeps $[9,10]$. With the final aim of defining the potential of commercial application of Peps as tool for enhancement of the resistance of Rosaceae plants to pathogens, here we determined the efficacy of PpPeps in vivo. In addition, we used transcriptome deep sequencing to further analyze the peach response to topical application of peach Peps, specifically at doses that efficiently protect $P$. persica leaves against Xap infection.

\section{Results}

PpPep1 and PpPep2 protect Prunus plants against the bacterial pathogen Xap

We previously used an ex vivo approach to demonstrate that topical application of PpPep1 and PpPep2 protected $P$. persica $\times P$. dulcis leaves against the phytopathogen Xap. Optimal efficiencies were on treatment with 0.1 and $1 \mu \mathrm{M}$ doses 24 and $48 \mathrm{~h}$ prior to pathogen challenge. Here we assessed the efficiency of treatment with the same peptides to protect Prunus against the same phytopathogen in plants grown in the greenhouse. Intact $P$. persica $\times$ P. dulcis plants were treated with water or the chemically synthesized PpPep1 and PpPep2, 24h before the inoculation with $10^{8} \mathrm{cfu} / \mathrm{mL}$ Xap.

Leaves treated with water showed the typical symptoms of bacterial spot infection. About 1 week after Xap inoculation, infection became apparent as small, palegreen to yellow, circular or irregular areas with a light tan center. Over time, symptoms developed, with an increase in number and size of the spots, becoming more angular in shape and brown or black with a yellow halo. The lesions merged to cover up to a $50 \%$ of the leaf surface 4 weeks post bacterial inoculation, when leaves fell off from the plant. In contrast, application of PpPep1 
and PpPep2 resulted in a lower percentage of affected leaf surface at all time points assessed i.e. up to 3 weeks after infection. Figure 1 shows these differences 9 days after inoculation, as it was confirmed using KruskalWallis post-hoc pairwise comparisons (IMB SPSS Statistics 25, $p<0.05)$. This indicates that these treatments efficiently protected Prunus plants from Xap. Moreover, there was a dose-dependent effect on plant protection. For PpPep2, 1 and $10 \mu \mathrm{M}$ doses resulted in $40 \%$ reduction of the Xap symptoms 9 days after infection (Fig. 1). The maximum protection with PpPep1 was achieved at $0.1 \mu \mathrm{M}$ doses. Thus, $0.1 \mu \mathrm{M}$ PpPep1 and $1 \mu \mathrm{M}$ PpPep2 concentrations were selected for further experiments.

\section{RNA-Seq characterization of peach transcriptomic response to PpPep1 and PpPep2}

To characterize the peach response to preventive treatment with PpPep1 and PpPep2 we treated juvenile $P$. persica plants with the most effective dose of each peptide and sequenced their transcriptomes after 1, 24 and $48 \mathrm{~h}$ using untreated plants as control. Data supporting this analysis is available in the Gene Expression Omnibus (GEO) repository, record GSE161802 (https://www.ncbi.nlm.nih.gov/geo/query/ acc.cgi?acc $=$ GSE161802).

Additional file 1 shows summary mapping statistics of RNA sequencing to the $P$. persica reference genome. There were on average 55 million 75 bp paired stranded reads, for each experimental replicate. The percentage of 91\% paired mapped of reads indicated appropriate quality of the libraries. On average, about $95 \%$ of the read pairs aligned to exonic locations in the reference genome, while slightly more than $1 \%$ aligned to intronic regions, suggesting new isoforms, presence of pre-mRNA or imprecise transcript length prediction. Less than 5\% read pairs aligned to intergenic regions, which might

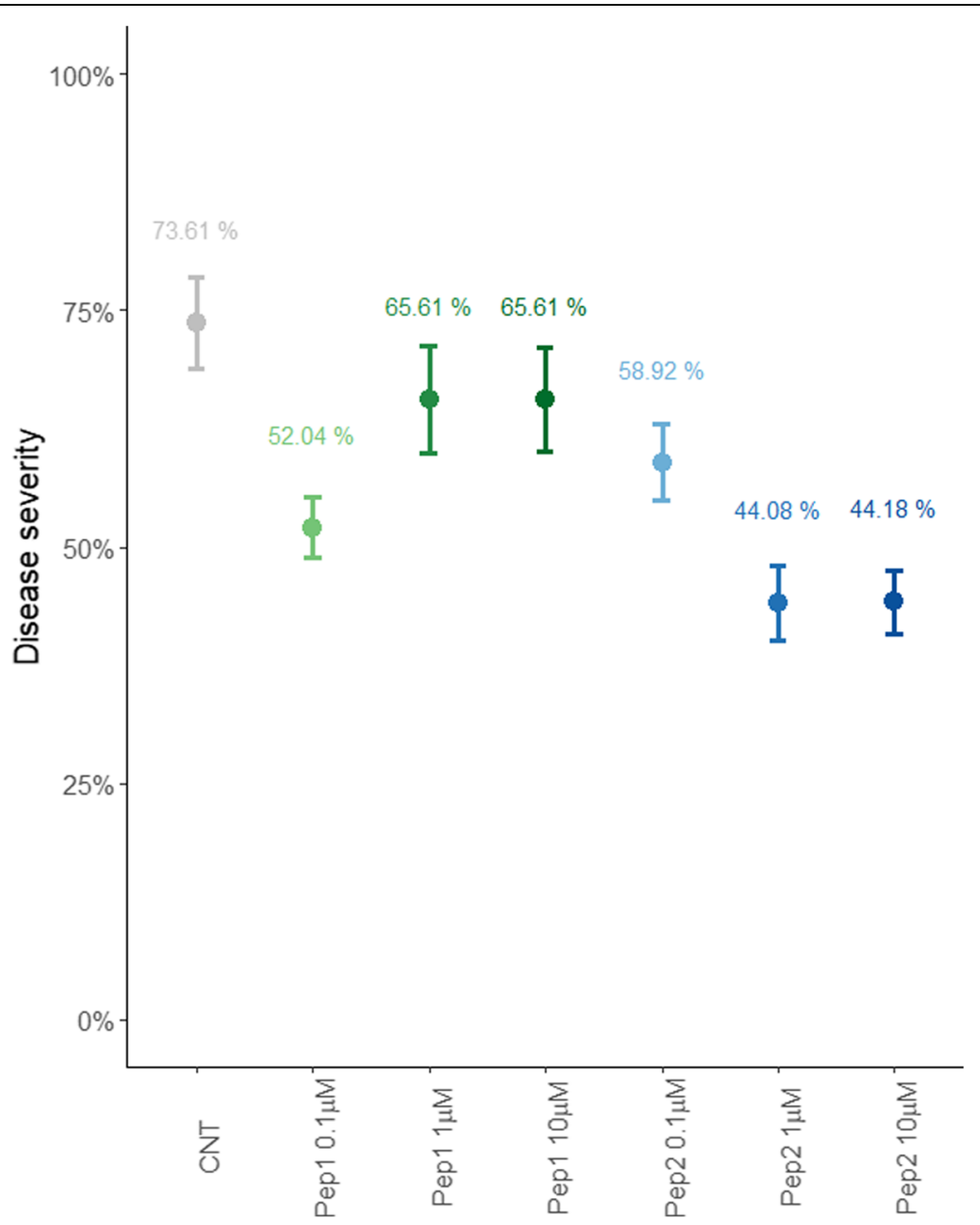

Fig. 1 Disease severity in P. persica $\times$ P. dulcis plants treated with different concentrations of PpPep1 and PpPep2 for $24 \mathrm{~h}$, prior to infection with $10^{8} \mathrm{cfu} / \mathrm{mL}$ Xap, in relation to untreated plants (CNT). Data taken nine days after infection. Mean values and error bars shown. Sample size: three biological replicates, for each measurement on the tree leaves; for each of the six treatments (Pep1: green, Pep2: blue) and one control (grey) 
correspond to yet unannotated genes in the peach genome. Other good library quality indicators were that about $25 \%$ of genes consumed $25 \%$ of reads, the percentage of PCR duplicates (28-36\%) and the high proportion of reads (uniquely paired-end mapped reads) mapping to protein coding regions ( $>99 \%$ ) [29]. Of 24,898 genes in the $P$. persica NCBIv2.38 genome, more than 20,500 were covered by at least one read pair in each sample.

Specific RT-qPCR assays were developed to target 19 genes belonging to 18 out of 49 differential functional categories (BINs, Additional file 2) and displaying above 1000 counts at least in one sample. RNA levels were assessed in peach leaf samples obtained as for the RNASeq experiments, 0, 1, 24 and $48 \mathrm{~h}$ after PpPep1 and PpPep2 topical application. High correlation of differential gene expression between RNA-Seq and RT-qPCR data was observed (Pearson correlation of 0.92), validating the relative quantification performance of RNA-Seq results (Additional file 2).

\section{PpPep1 and PpPep2 elicit similar transcriptomic} responses

Principal Component Analysis (PCA) of the processed data (Fig. 2 and Additional file 3) shows that the main transcriptomic changes can be attributed to the treatment time-course condition and not to the specific peptide. The transcriptomes of peach leaves sampled at the same time-points after treatment with either PpPep1 or PpPep2 were not separated across a three-dimensional PCA scatterplot (Fig. 2 and Additional file 3), while PC1, PC2 or PC3 together explained up to $93.69 \%$ of the overall data variability.

Differential expression analysis was carried out on the basis of normalized gene reads using DESeq 2 and adjusted $p$ value (adj. p) threshold $<0.01$. To highlight the time-course responses, transcriptomes of plants treated with PpPep1 or PpPep2 for a certain period of time were compared to those corresponding to the previous timepoint. In a complementary approach using RT-qPCR, no

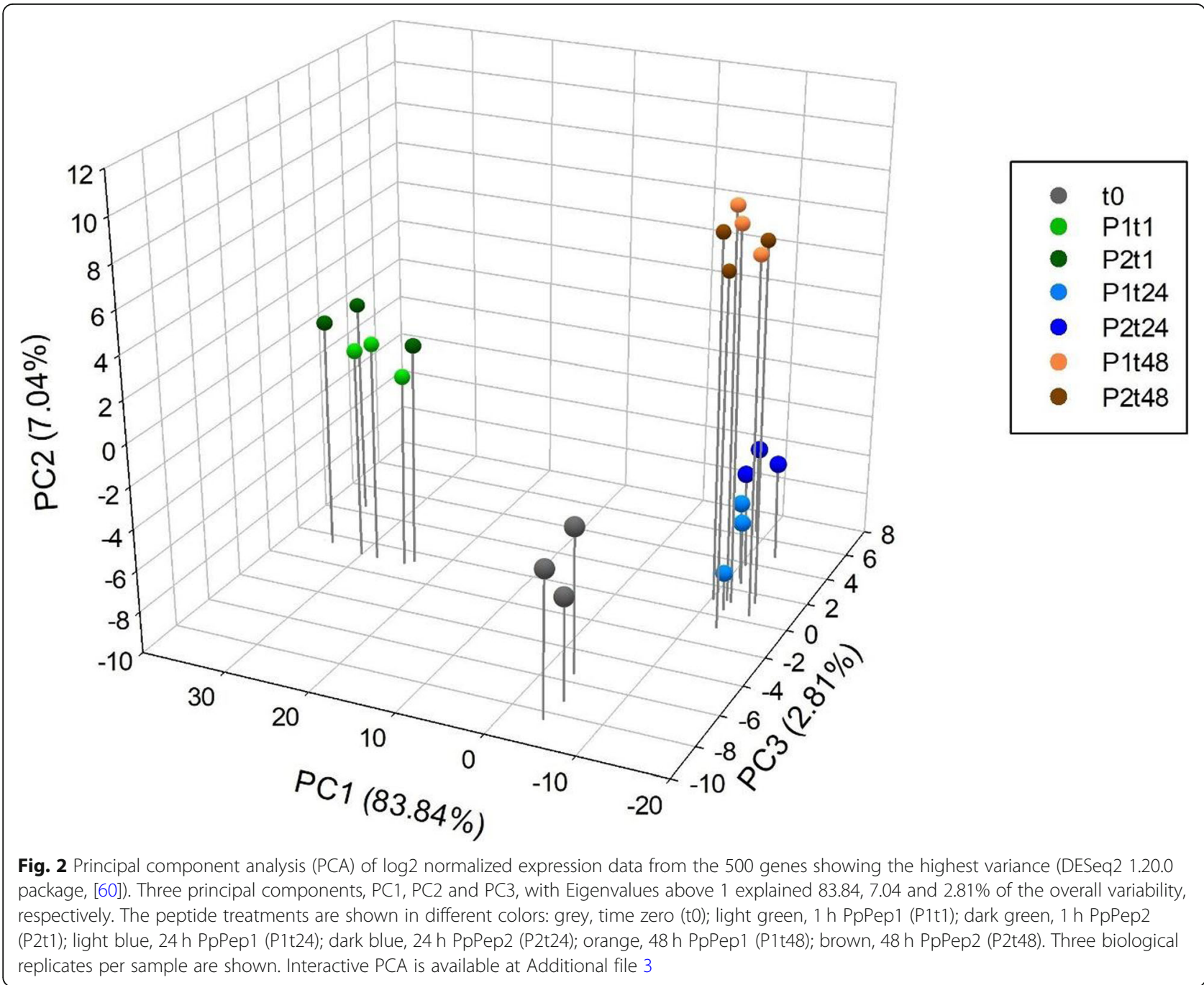


significant changes in gene expression between mock plants sampled at $0,1,24$ and $48 \mathrm{~h}$ time-points were detected ( $p>0.01$, IBM SPSS statistics 25; Additional file 4).

Figure 3 and Additional file 5 summarize differentially expressed genes (DEG) results in response to PpPeps. We identified a total of 2076 genes exhibiting differential expression upon PpPep1 application and 1985 for PpPep2, accounting for $8 \%$ of the P. persica genes. Overall, $6 \%$ of peach genes (1464) were regulated in response to both peptides. The similitude of response to PpPep1 and PpPep2 reached 80 and $89 \%$ of the total amount of DEG and tended to decrease with time, to 74 and $68 \%$ DEG 1 day after treatment, and to 69 and 57\% DEG 2 days after treatment.

One hour after Pep application there was regulation of ca. $5 \%$ peach genes, with more than $90 \%$ upregulated (Fig. 3 and Additional files 5 and 6). One day after Pep treatment DEG also encompassed ca. $5 \%$ of the total $P$. persica genes, among which ca. $80 \%$ were downregulated (Fig. 3, Additional files 5 and 6). For about 20\% DEG, which accounts for $1.2 \%$ of the peach genes, regulation was first detected 1 day after Pep application (Fig. 3). Another 24 and 14\% DEG, for PpPep1 and PpPep2 respectively, were first detected 2 days after treatment (Fig. 3). This set of late DEG agrees with PC2 (Fig. 2 and Additional file 3).

The expression patterns of all 2542 genes with differential expression in at least one treatment (i.e. PpPep1 or PpPep2 application for 1, 24 or $48 \mathrm{~h}$ ) are represented as a cluster heat map (Fig. 4 and Additional file 7).

\section{Analysis of the peach transcriptomic response to PpPeps on the level of processes}

RNA-Seq gene expression data was subjected to gene set enrichment analysis to assist biological interpretation of transcriptome changes in response to Peps running the
Singular Enrichment Analysis (SEA) within the GSEA toolkit [30]. As shown in Table 1 and Additional files 8 and 9, 49 BINs were enriched at least in one condition, comprising of 1194 enrichment contributor genes. Numerous BINs and SUBBINs showed upregulation $1 \mathrm{~h}$ after peptide application and downregulation 1 day later, in response to both PpPep1 and PpPep2, describing an initial and transient transcriptomic response to PpPeps. Another set of BINs were enriched 2 days after treatment with Peps.

\section{Dynamic visualization of RNA-Seq results}

$P$. persica specific background knowledge network was built based upon the first neighbors of the validationselected genes and published connections within the Arabidopsis thaliana comprehensive knowledge network [31]. This led to a P. persica Pep background knowledge network with 629 nodes and 7393 edges. To make the visualization of the transcriptomics rewiring events and the dynamics of the underlying system more exploratory and biologically informative, this initial background network was further clustered using the DiNAR sub-app. Post clustering step, the most informative cluster was selected, i.e. cluster 2. Hence cluster 2 from the P. persica Pep background knowledge network lastly contained 195 nodes and 1698 edges that represented the most expressive and dynamic transcripts. Relative gene expression data sets 1,24 and $48 \mathrm{~h}$ after treatment with PpPep1 and PpPep2 (each compared to untreated samples) were superimposed on $P$. persica Pep background knowledge network using DiNAR. Figure 5 shows a static visualization of our peach tree dataset superimposed on cluster 2 from this network. Dynamic data, together with further information on every node (gene code) and edge connection type (e.g. transcriptional
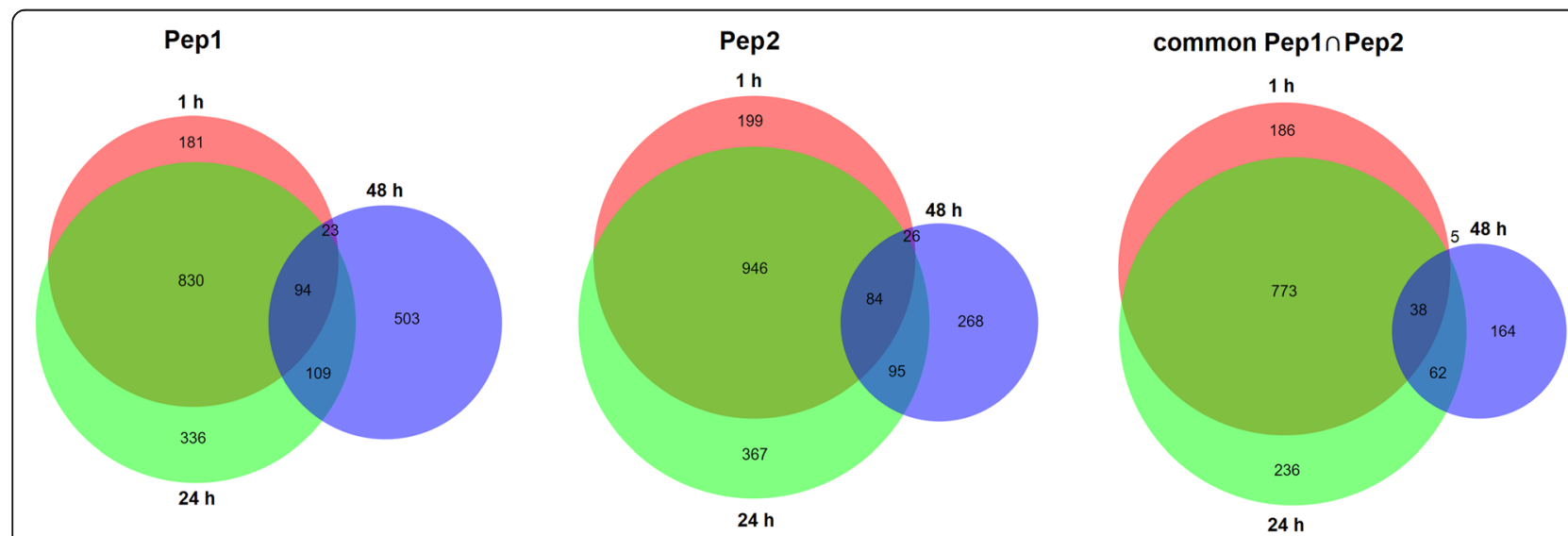

Fig. 3 Venn diagrams representing overlapping differentially expressed genes in response to PpPep1 (left panel) and PpPep2 (middle panel), as well as genes commonly regulated in both treatments (right panel). 1 h: 1 h vs. control; 24 h: 24 h vs. 1 h; 48 h: 48 h vs. 24 h; n: intersection i.e. common DEGs between comparisons. Additional file 6 shows Venn diagrams considering upregulated and downregulated gene numbers 


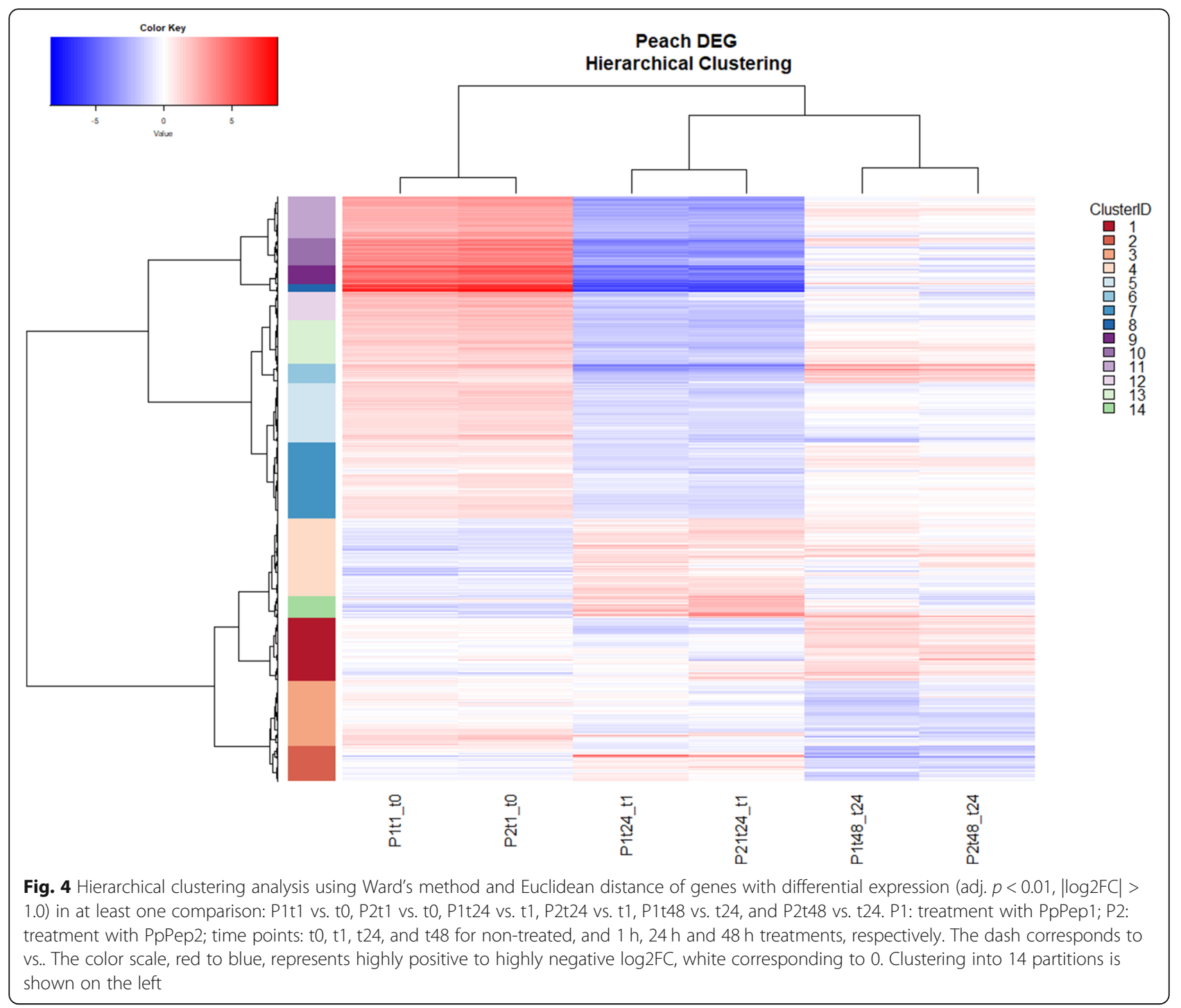

regulation) is presented in the Additional files 10 and 11.

\section{Comparison of the transcriptomic responses to PpPep1 and PpPep2}

We used the GSEA tool for more detailed information on the differences between PpPep1 and PpPep2 inspected using DiNAR (Table 2). Note that these differences do not exceed the 6.31\% (Fig. 2 and Additional file 3 ) of the variability in the transcriptomic data. Direct comparison of the transcriptomes of $P$. persica leaves treated with either PpPep1 or PpPep2 (Additional file 8) shows some statistically enriched BINs, mainly $1 \mathrm{~h}$ and 1 day after treatment. These BINs were mostly enriched at just one time point, suggesting the variations between the two peptides were temporary. More than $80 \%$ of the genes contributing to the enrichment of these BINs in the PpPep1 vs. PpPep2 comparison were overrepresented in the time course comparisons Peps response (Table 1). This suggests that differences between PpPep1 and PpPep2 result primarily from either shifted expression changes or different expression levels in the same gene set and/or gene type, with only e.g. slightly different expression of genes that have been related to environmental stresses (Table 2).

\section{Comparison of the responses to Peps and pathogens}

Using the same background knowledge network, we compared the response dynamics to Peps and pathogen infection in DiNAR. We superimposed onto the $P$. persica Pep background knowledge network two published transcriptome datasets: (i) A. thaliana leaves 2 and $10 \mathrm{~h}$ after treatment with the compatible AtPep1 [22] and (ii) A. thaliana leaves 2 and $17.5 \mathrm{~h}$ after infection with the pathogenic bacterium Pseudomonas syringae pv. tomato DC3000 (Pst) [32]. Figure 6a, b and Additional files 12 
Table 1 Time-course transcriptome response of P. persica leaves to treatment with PpPep1 and PpPep2

\begin{tabular}{|c|c|c|c|c|c|}
\hline \multirow{2}{*}{ BIN NAME } & \multirow{2}{*}{ SIZE } & t1_to & t24_t1 & \multicolumn{2}{|c|}{ t48_t24 } \\
\hline & & \begin{tabular}{l|l|l|l|l} 
Pep1 & Pep2 \\
\end{tabular} & \begin{tabular}{l|l|l} 
Pep1 & Pep2 \\
\end{tabular} & Pep1 & Pep2 \\
\hline 11.9 LIPID METABOLISM.LIPID DEGRADATION & 138 & & & & \\
\hline 11.9.3 LIPID METABOLISM.LIPID DEGRADATION.LYSOPHOSPHOLIPASES & 82 & & & & \\
\hline 11.9.3.3 LIPID METABOLISM.LIPID & & & & & \\
\hline DEGRADATION.LYSOPHOSPHOLIPASES.GLYCEROPHOSPHODIESTER PHOSPHODIESTERASE & 40 & & & & \\
\hline 27.3 RNA.REGULATION OF TRANSCRIPTION & & & & & \\
\hline 27.3.21 RNA.REGULATION OF TRANSCRIPTION.GRAS TRANSCRIPTION FACTOR FAMILY & 24 & & & & \\
\hline 27.3.22 RNA.REGULATION OF TRANSCRIPTION.HOMEOBOX TRANSCRIPTION FACTOR FAMILY & & & & & \\
\hline (HB) & 47 & & & & \\
\hline 27.3.32 RNA.REGULATION OF TRANSCRIPTION.WRKY DOMAIN TRANSCRIPTION FACTOR & & & & & \\
\hline FAMILY & 49 & & & & \\
\hline 27.3.41 RNA.REGULATION OF TRANSCRIPTION.B3 TRANSCRIPTION FACTOR FAMILY & 16 & & & & \\
\hline 27.3.44 RNA.REGULATION OF TRANSCRIPTION.CHROMATIN REMODELING FACTORS & 72 & & & & \\
\hline 28.1.1 DNA.SYNTHESIS/CHROMATIN STRUCTURE.RETROTRANSPOSON/TRANSPOSASE & 54 & & & & \\
\hline 28.1.1.4 DNA.SYNTHESIS/CHROMATIN STRUCTURE.RETROTRANSPOSON/TRANSPOSASE.HAT- & & & & & \\
\hline LIKE TRANSPOSASE & 43 & & & & \\
\hline 30 SIGNALLING & & & & & \\
\hline 30.1 SIGNALLING.IN SUGAR AND NUTRIENT PHYSIOLOGY & 46 & & & & \\
\hline 30.1.1 SIGNALLING.IN SUGAR AND NUTRIENT PHYSIOLOGY.MISC & 45 & & & & \\
\hline 30.2 SIGNALLING.RECEPTOR KINASES & & & & & \\
\hline 30.2.11 SIGNALLING.RECEPTOR KINASES.LEUCINE RICH REPEAT XI & 52 & & & & \\
\hline 30.2.16 SIGNALLING.RECEPTOR KINASES.CATHARANTHUS ROSEUS-LIKE RLK1 & 27 & & & & \\
\hline 30.2.17 SIGNALLING.RECEPTOR KINASES.DUF 26 & 42 & & & & \\
\hline 30.2.19 SIGNALLING.RECEPTOR KINASES.LEGUME-LECTIN & 17 & & & & \\
\hline 30.2.25 SIGNALLING.RECEPTOR KINASES.WALL ASSOCIATED KINASE & 23 & & & & \\
\hline 30.2.3 SIGNALLING.RECEPTOR KINASES.LEUCINE RICH REPEAT III & 34 & & & & \\
\hline 30.3 SIGNALLING.CALCIUM & 208 & & & & \\
\hline 33.2 DEVELOPMENT.LATE EMBRYOGENESIS ABUNDANT & 60 & & & & \\
\hline 34.21 TRANSPORT.CALCIUM & 21 & & & & \\
\hline 20 STRESS & & & & & \\
\hline 20.1.2 STRESS.BIOTIC.RECEPTORS & 451 & & & & \\
\hline 20.1.2.1 STRESS.BIOTIC.RECEPTORS.CC-NBS-LRR & 162 & & & & \\
\hline 20.1.2.2 STRESS.BIOTIC.RECEPTORS.TIR-NBS-LRR & 119 & & & & \\
\hline 20.1.7.1 STRESS.BIOTIC.PR-PROTEINS.PR1 (ANTIFUNGAL) & 16 & & & & \\
\hline 20.1.7.5 STRESS.BIOTIC.PR-PROTEINS.PR5 (THAUMATIN-LIKE PROTEINS) & 29 & & & & \\
\hline 20.2.3 STRESS.ABIOTIC.DROUGHT/SALT & 49 & & & & \\
\hline 17 HORMONE METABOLISM & & & & & \\
\hline 17.1 HORMONE METABOLISM.ABSCISIC ACID & 51 & & & & \\
\hline 17.1.2 HORMONE METABOLISM.ABSCISIC ACID.SIGNAL TRANSDUCTION & 16 & & & & \\
\hline 17.5 HORMONE METABOLISM.ETHYLENE & 75 & & & & \\
\hline 17.5.2 HORMONE METABOLISM.ETHYLENE.SIGNAL TRANSDUCTION & 44 & & & & \\
\hline 29 PROTEIN & & & & & \\
\hline 29.4.1.57 PROTEIN.POSTRANSLATIONAL MODIFICATION.KINASE.RECEPTOR LIKE & & & & & \\
\hline CYTOPLASMATIC KINASE VII & 27 & & & & \\
\hline 29.2.1 PROTEIN.SYNTHESIS.RIBOSOMAL PROTEIN & 323 & & & & \\
\hline 3.2 MINOR CHO METABOLISM.TREHALOSE & 31 & & & & \\
\hline 3.2.3 MINOR CHO METABOLISM.TREHALOSE.POTENTIAL TPS/TPP & 23 & & & & \\
\hline 10 CELL WALL & 287 & & & & \\
\hline 10.1 CELL WALL.PRECURSOR SYNTHESIS & 40 & & & & \\
\hline 10.5 CELL WALL.CELL WALL PROTEINS & 44 & & & & \\
\hline 10.5.1 CELL WALL.CELL WALL PROTEINS.AGPS & 16 & & & & \\
\hline 10.5.1.1 CELL WALL.CELL WALL PROTEINS.AGPS.AGP & 15 & & & & \\
\hline 10.6 CELL WALL.DEGRADATION & 102 & & & & \\
\hline 10.6.2 CELL WALL.DEGRADATION.MANNAN-XYLOSE-ARABINOSE & 27 & & & & \\
\hline
\end{tabular}

Gene set enrichment analysis was carried out using GSEA and adjusted $p<0.01$. For every peptide (PpPep1 and PpPep2), samples treated for 1, 24 and $48 \mathrm{~h}$ were compared to those corresponding to the previous time-point [first vs. second time (t) condition in the first row]. Red and blue indicate upregulation and downregulation, respectively, of the genes contributing to each bin. Bright red and blue indicate statistically significant enrichment. Blank, light red and light blue cells indicate the absence of statistically significant enrichment. Size indicates the number of genes in the gene set after filtering out those not in the expression dataset. Additional file 8 shows the data for all BINs and comparisons and Additional file 9 has detailed information about all genes contributing to each BIN enrichment

and 13 show a visualization of the two transcriptome pattern dynamics, identification of strong differential interactions and recall of common effects. Node location and BIN representation are unique in a given context, allowing for a straightforward comparison between samples.

\section{Discussion}

Several studies have demonstrated that pre-treatment of Peps significantly improves plants resistance to pathogens $[1,3,6,7,9,12]$ and we have previously determined that low doses of topical application of Rosaceae Peps efficiently enhance resistance of Prunus spp. to Xap infection [9] in an ex vivo system. Here we showed that PpPep1 and PpPep2 are also effective in vivo, which strengthens their candidacy for an actual environmental-friendly strategy to enhance plant resistance. The protective effect of topical application occurred at nanomolar concentrations of either PpPep1 or PpPep2, decreasing the deleterious consequences of 


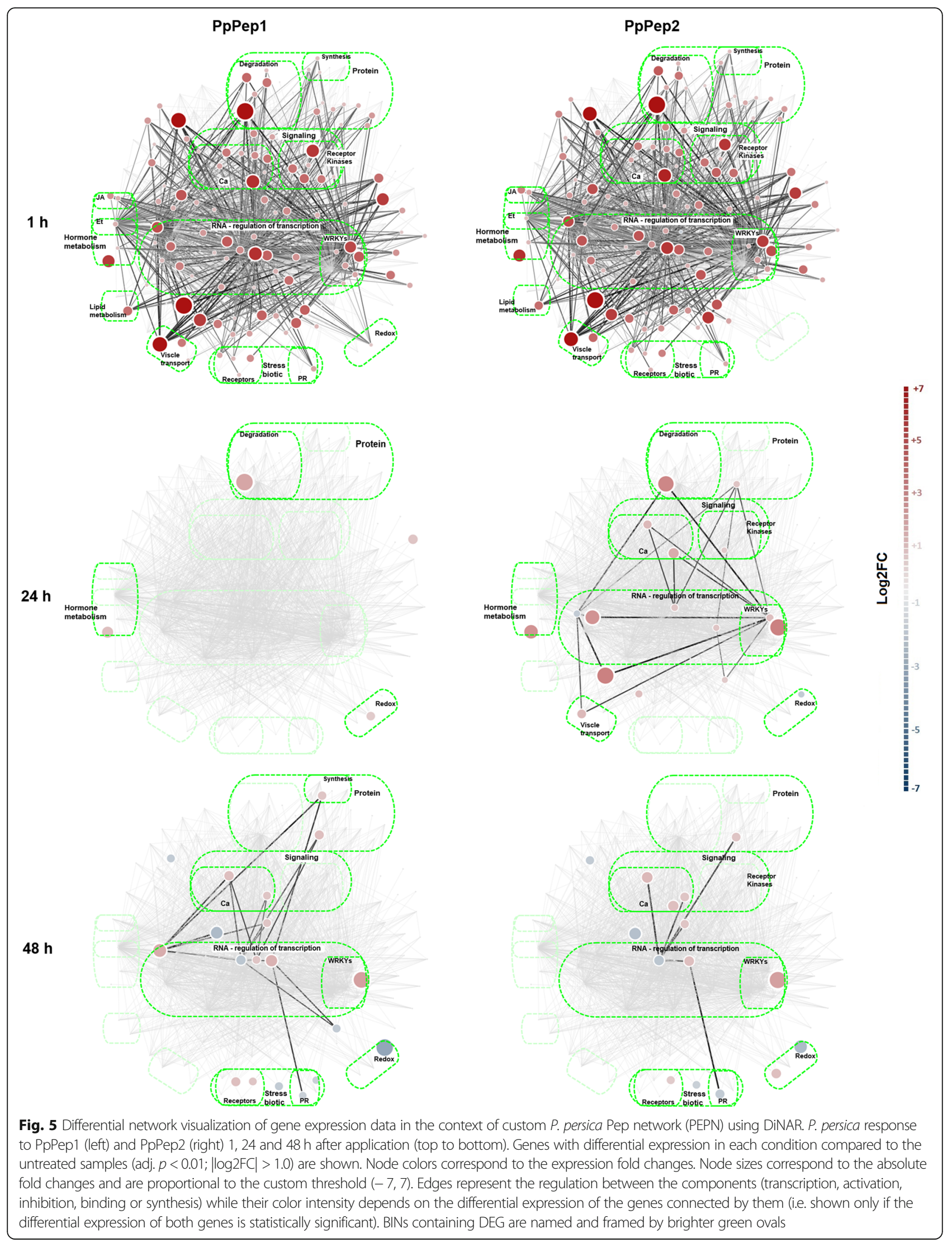


Table 2 Comparison of the transcriptome response of $P$. persica leaves to PpPep1 and PpPep2

\begin{tabular}{|c|c|c|c|c|}
\hline \multirow{2}{*}{ BIN NAME } & \multirow{2}{*}{ SIZE } & \multicolumn{3}{|c|}{ Pep1 vs Pep2 } \\
\hline & & $1 \mathrm{~h}$ & $24 \mathrm{~h}$ & $48 \mathrm{~h}$ \\
\hline $1 \mathrm{PS}$ & 191 & & & \\
\hline 1.1 PS.LIGHTREACTION & 108 & & & \\
\hline 1.1.1 PS.LIGHTREACTION.PHOTOSYSTEM II & 49 & & & \\
\hline 1.1.1.2 PS.LIGHTREACTION.PHOTOSYSTEM II.PSIII POLYPEPTIDE SUBUNITS & 35 & & & \\
\hline 1.1.2 PS.LIGHTREACTION.PHOTOSYSTEM I & 19 & & & \\
\hline 3.2 MINOR CHO METABOLISM.TREHALOSE & 31 & & & \\
\hline 3.2.3 MINOR CHO METABOLISM.TREHALOSE.POTENTIAL TPS/TPP & 23 & & & \\
\hline 10 CELL WALL & 287 & & & \\
\hline 10.5 CELL WALL.CELL WALL PROTEINS & 44 & & & \\
\hline 11.5 LIPID METABOLISM.GLYCEROL METABOLISM & 199 & & & \\
\hline 11.5.2 LIPID METABOLISM.GLYCEROL METABOLISM.GLYCEROL-3-PHOSPHATE DEHYDROGENASE (NAD+) & 197 & & & \\
\hline 11.9 LIPID METABOLISM.LIPID DEGRADATION & 138 & & & \\
\hline 11.9.3.3 LIPID METABOLISM.LIPID DEGRADATION.LYSOPHOSPHOLIPASES.GLYCEROPHOSPHODIESTER & & & & \\
\hline PHOSPHODIESTERASE & 40 & & & \\
\hline 12 N-METABOLISM & 26 & & & \\
\hline 16.10 SECONDARY METABOLISM.SIMPLE PHENOLS & 19 & & & \\
\hline 17 HORMONE METABOLISM & & & & \\
\hline 17.7 HORMONE METABOLISM.JASMONATE & 30 & & & \\
\hline 20 STRESS & & & & \\
\hline 20.1.2 STRESS.BIOTIC.RECEPTORS & 451 & & & \\
\hline 20.1.2.2 STRESS.BIOTIC.RECEPTORS.TIR-NBS-LRR & 119 & & & \\
\hline 20.1.7 STRESS.BIOTIC.PR-PROTEINS & 113 & & & \\
\hline 20.1.7.3 STRESS.BIOTIC.PR-PROTEINS.PR3/4/8/11 (CHITINASES AND CHITIN BINDING PROTEINS) & 26 & & & \\
\hline 20.1.7.5 STRESS.BIOTIC.PR-PROTEINS.PR5 (THAUMATIN-LIKE PROTEINS) & 29 & & & \\
\hline 20.2.4 STRESS.ABIOTIC.TOUCH/WOUNDING & 20 & & & \\
\hline 21.4 REDOX.GLUTAREDOXINS & 32 & & & \\
\hline 26 MISC & & & & \\
\hline 26.1 MISC.MISC2 & 205 & & & \\
\hline 26.4 MISC.BETA 1,3 GLUCAN HYDROLASES & 46 & & & \\
\hline 26.4.1 MISC.BETA 1,3 GLUCAN HYDROLASES.GLUCAN ENDO-1,3-BETA-GLUCOSIDASE & 41 & & & \\
\hline 27.3 RNA.REGULATION OF TRANSCRIPTION & & & & \\
\hline 27.3.6 RNA.REGULATION OF TRANSCRIPTION.BASIC HELIX-LOOP-HELIX FAMILY (BHLH) & 291 & & & \\
\hline 27.3.24 RNA.REGULATION OF TRANSCRIPTION.MADS BOX TRANSCRIPTION FACTOR FAMILY & 24 & & & \\
\hline 27.3.32 RNA.REGULATION OF TRANSCRIPTION.WRKY DOMAIN TRANSCRIPTION FACTOR FAMILY & 49 & & & \\
\hline 27.3.44 RNA.REGULATION OF TRANSCRIPTION.CHROMATIN REMODELING FACTORS & 72 & & & \\
\hline 28 DNA & & & & \\
\hline 28.1.1 DNA.SYNTHESIS/CHROMATIN STRUCTURE.RETROTRANSPOSON/TRANSPOSASE & 54 & & & \\
\hline 28.1.1.4 DNA.SYNTHESIS/CHROMATIN STRUCTURE.RETROTRANSPOSON/TRANSPOSASE.HAT-LIKE TRANSPOSASE & 43 & & & \\
\hline 28.99 DNA.UNSPECIFIED & 281 & & & \\
\hline 29 PROTEIN & & & & \\
\hline 29.2.1 PROTEIN.SYNTHESIS.RIBOSOMAL PROTEIN & 323 & & & \\
\hline 29.2.1.1.1 PROTEIN.SYNTHESIS.RIBOSOMAL PROTEIN.PROKARYOTIC.CHLOROPLAST & 56 & & & \\
\hline 29.2.1.1 PROTEIN.SYNTHESIS.RIBOSOMAL PROTEIN.PROKARYOTIC & 109 & & & \\
\hline 29.2.1.2 PROTEIN.SYNTHESIS.RIBOSOMAL PROTEIN.EUKARYOTIC & 195 & & & \\
\hline 29.2.1.2.1 PROTEIN.SYNTHESIS.RIBOSOMAL PROTEIN.EUKARYOTIC.4OS SUBUNIT & 79 & & & \\
\hline 29.2.1.2.2 PROTEIN.SYNTHESIS.RIBOSOMAL PROTEIN.EUKARYOTIC.6OS SUBUNIT & 113 & & & \\
\hline 30 SIGNALLING & & & & \\
\hline 30.1 SIGNALLING.IN SUGAR AND NUTRIENT PHYSIOLOGY & 46 & & & \\
\hline 30.1.1 SIGNALLING.IN SUGAR AND NUTRIENT PHYSIOLOGY.MISC & 45 & & & \\
\hline 30.2.8 SIGNALLING.RECEPTOR KINASES.LEUCINE RICH REPEAT VIII & 38 & & & \\
\hline 30.2.8.2 SIGNALLING.RECEPTOR KINASES.LEUCINE RICH REPEAT VIII.TYPE 2 & 26 & & & \\
\hline 30.2.11 SIGNALLING.RECEPTOR KINASES.LEUCINE RICH REPEAT XI & 52 & & & \\
\hline 31.3 CELL.CYCLE & 293 & & & \\
\hline 31.3.1 CELL.CYCLE.PEPTIDYLPROLYL ISOMERASE & 222 & & & \\
\hline 33.2 DEVELOPMENT.LATE EMBRYOGENESIS ABUNDANT & 60 & & & \\
\hline 34.12 TRANSPORT.METAL & 68 & & & \\
\hline 34.21 TRANSPORT.CALCIUM & 21 & & & \\
\hline
\end{tabular}

Gene set enrichment analysis was carried out using GSEA and adjusted $p<0.01$. Orange and green indicate overexpression on PpPep1 and PpPep2 treatment, respectively, of the genes contributing to each bin. Blank cells indicate the absence of statistically significant enrichment. Size indicates the number of genes in the gene set after filtering out those not in the expression dataset. Additional file 8 shows the data for all BINs and comparisons

massive Xap inoculation onto peach plants that were challenged with pathogen concentrations of $10^{8} \mathrm{cfu} / \mathrm{mL}$, i.e. higher than expected in nature. In these extreme conditions, the infection symptoms were reduced by up to $40 \%$. Interestingly, some indicators showed a prolongation of this protection when more moderated infections occurred. We observed a dose-dependent effect on plant protection. For PpPep2, 1 and $10 \mu \mathrm{M}$ were the most effective doses reducing Xap symptoms 9 days after massive infection (Fig. 1). Unexpectedly, the maximum protection with PpPep1 was achieved at $0.1 \mu \mathrm{M}$ doses, suggesting that peach has a higher sensitivity to PpPep1 perception which could be interesting for field application strategies.

We analyzed the peach response to topical application of peach Peps through RNA-Seq, which allowed us to characterize the immune triggering and provided as well detailed transcriptomics information that would facilitate 


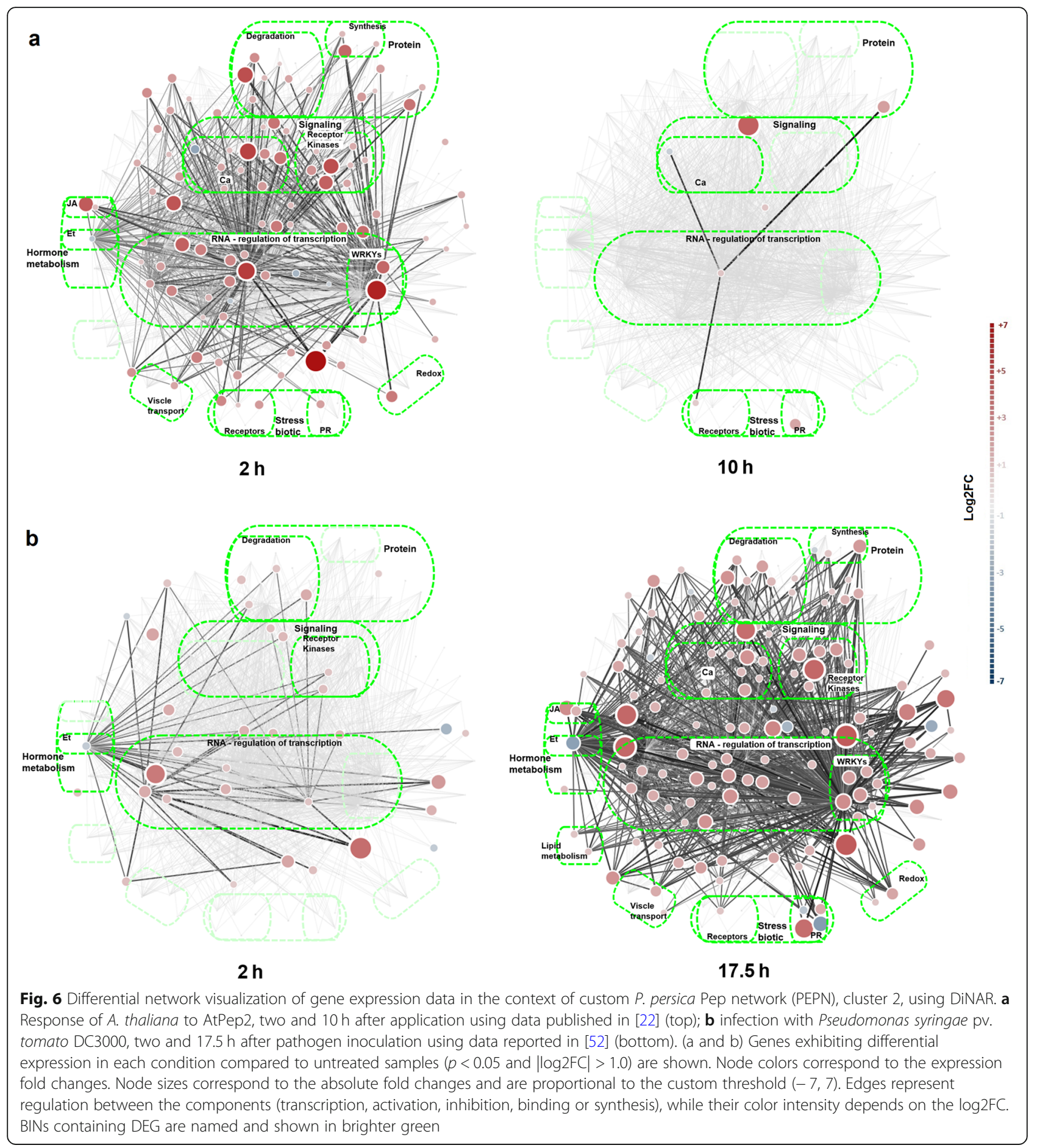

identification of any unwanted effect that could rise food safety concerns.

Overall, up to $8 \%$ of the $P$. persica genes were regulated in response to PpPeps. The numbers of DEG shared under both $1 \mathrm{~h}$ and $24 \mathrm{~h}$ conditions indicated a transient transcription induction shortly after peptide application that affected up to $4 \%$ of $P$. persica genes (Fig. 3 and Additional files 5 and 6). Up to $6 \%$ of the peach genes were commonly altered after topical application of PpPep1 and PpPep2 (Fig. 3 and Additional files 5 and 6), which demonstrated a highly similar transcriptomic response up to 2 days after exposure to the peptides, especially shortly after treatment $(1 \mathrm{~h})$. At later stages we observed some asynchrony and variation in the specific regulated genes, still within the same functional categories (Table 2). This supports the observed 
differences of PpPep1 and PpPep2 in reducing Xap infection severity.

DiNAR integration and custom background knowledge network allowed us a dynamic visualization of the transcriptomes of peach leaves upon treatment with PpPeps (Fig. 5 and Additional files 10 and 11). It showed the aforementioned shared, strong response to PpPep1 and PpPep2 1 hour after application, with virtually the same network rewiring events. One day after peptide application there was deregulation of most nodes, nearly reaching control levels in the case of PpPep1 treatment. Two days after treatment the regulated gene set was largely different from that observed before. There was evident decrease in the similitude between the responses to PpPep1 and PpPep2 one and 2 days after treatment, which seemed to reflect a difference in the rhythm of gene regulation, PpPep2 being slower than PpPep1. This is in agreement with our PCA (Fig. 2 and Additional file 3) showing that $93.69 \%$ variability of our RNA-Seq results depends on the time course; and that samples of peach leaves treated with either PpPep1 or PpPep2 for a given period of time are not separated by any PC.

A gene set enrichment analysis was carried out with GSEA to describe the transcriptomic response to PpPeps in detail. It was confirmed that, during the whole-time course, both PpPep1 and PpPep2 induced major regulation in functional categories related to activation of PTI (Table 1). The identity of regulated BINs is in agreement with the described responses of Arabidopsis to its specific AtPeps [21, 22] and suggests that in general terms, Pep responses in commercial species such as peach are similar to the model species.

Pep perception occurs via the corresponding PEPRs. The peach PEPR gene family encompasses PEPR1a and PEPR1b $[3,9]$. They cluster in SUBBIN 30.2.11, comprised of leucine-rich repeat receptor kinases (LRR-RK) of the subfamily XI, involved in plant development and differentiation [12]. Both results, our RNA-Seq and RTqPCR, showed no detectable expression of PpPEPR1a or PpPEPR1b in untreated leaf blades. This is similar to the Arabidopsis AtPEPR gene family, for which a basal expression in leaves was restricted to the veins [2, 25, 33]. One hour after PpPep1 or PpPep2 treatment, strong induction of PpPEPR1a (Prupe.3G167800), but not PpPEPR1b (Prupe.3G167900), was observed. AtPEPR1 and AtPEPR2 expression overlap to some degree, but in general they have different expression patterns. AtPEPR1 has been shown to be induced by application of any AtPep, whereas AtPEPR2 transcript levels rise upon treatment with only few AtPeps [12]. Safaeizadeh and Boller [25] showed that the AtPEPR1 (but not AtPEPR2) promoter drove GUS accumulation $1 \mathrm{~h}$ after AtPep1 or flg22 treatment in leaves. Our results suggest that PpPEPR1a has a role in driving PpPep1 and PpPep2 signal transduction in peach tree leaves, and perhaps both PpPeps might be recognized by PpPEPR1a in leaves. Similarly, in Arabidopsis, AtPEPR1 can detect all eight AtPeps (AtPEPR2 detects only AtPep1 and AtPep2, [2]).

SUBBIN 20.1.2. (biotic stress sensing receptors) exhibited a similar pattern. Of special interest within this SUBBIN is FLS2, which recognizes a conserved $\mathrm{N}$ terminal 22-amino acid sequence (flg22) of bacterial flagellin as a PAMP. PEPR and FLS2 have strong similarities in structure and target recognition, and initiate pattern-triggered immunity (PTI) in a parallel way. In addition, not only AtPeps but also flg22 have been shown to induce the expression of AtPEPRs [25]. Here we demonstrate that, similar to Arabidopsis and AtPep1, peach leaves have a rapid, transient reaction to PpPeps inducing both PpPEPR1a and PpFLS2 (Prupe.3G304400) in a similar manner.

Several receptor-like cytoplasmic kinases (RLCKs) of the subfamily VII play key roles in PTI signaling. Botrytisinduced kinase1 (BIK1) and PBS1-like1 (PBL1) directly interact with RK such as PEPR1 and FLS2 [15, 34] and contribute to resistance to pathogens and herbivores [3537]. Other RLCK VII members have been suggested to contribute to the PTI. In peach an induction of RCLKs VII (including e.g. PBL1) expression which constitute the enriched BIN 29.4.1.57, was observed. This points towards their involvement in PpPep signal transduction similar to that described in the model species $[5,6,26,38]$.

The observed extensive transcriptional reprogramming following treatment with PpPeps included induction of genes with regulatory function, notably (i) those related to the hormone signaling, with special significance of ethylene (ET) and abscisic acid (ABA) hormone signal transduction (BINs 17.5.2 and 17.1.2, respectively); and (ii) those related to the regulation of transcription, particularly chromatin remodeling factors (BIN 27.3.44) and the WRKY transcription factor family (BIN 27.3.32). We identified 19 different WRKY transcriptional regulators with quick and transient upregulation upon persistent Pep application (Additional file 9). Proteins of this large family are characterized by the WRKY-domain and are involved in the regulation of plant resistance to a variety of pathogens in a complex regulatory network [39]. In agreement with our results, Pep sensing has been shown to involve several WRKYs e.g. WRKY33, which has been associated with AtPROPEP2 and AtPROPEP3 promoter activities [40].

In Arabidopsis and maize, PTI signaling cascade leads to the ET production in a matter of hours, as well as in a slight increase in the jasmonic acid (JA) [6, 13, 41]. In addition, Ross and colleagues [22] have described induction of ET and JA regulated genes in response to the AtPep2. Enrichment of BINs 17.5 and 17.5.2, 1 hour after the PpPep treatment of leaves, indicates that ET 
also plays an important role in the Pep signaling pathway in peach. These BINs contain genes responsible for ET biosynthesis e.g. 1-aminocyclopropane-1-carboxylate synthase and oxidase [42, 43]; and numerous ETresponsive transcription factors (ERF), which are the last layer of regulation of JA/ET-responsive defense genes [44] and can play a role in the resistance to necrotrophic pathogens. In contrast to MAMPs, AtPeps do not have major effects on SA synthesis but they co-activate both SA and JA/ET pathways in Arabidopsis, as they also trigger expression of several SA-induced genes [21, 22]. Our peach results and the PpPep system showed no enrichment of functional categories specifically linked to SA metabolism and signaling pathways. However, NDR1, a gene that belongs to the SA metabolism BIN and is required for antibacterial immunity [45], was significantly upregulated $1 \mathrm{~h}$ after treatment with any PpPep. In addition, the enriched BIN 20.1.7.1 gathered genes such as PR1 and PR4 that are considered markers for SA and ET/JA signaling, respectively, overexpressed 2 days after Pep exposure. The nonexpressor of PR genes1 (NPR1) (enriched BIN 20.2.1), which mediates resistance to biotrophic and hemi-biotrophic pathogens, is the main receptor of SA [46]. Abscisic acid (ABA) has multiple roles in abiotic and biotic stresses. It is primarily considered a negative regulator of disease resistance, through interference with signaling pathways of several other stressresponse hormones including JA and ET [47, 48]. In peach leaves, regulation of BIN 17.1.2 containing genes involved in ABA signal transduction suggests participation of ABA on fine tuning the response to PpPeps.

Here we found quick and transient upregulation of calcium signaling and calcium transport proteins (BINs 30.3 and 34.21, respectively). Calcium signaling is part of PTI, acting immediately downstream from FLS2 and BAK1. Changes in cytosolic $\mathrm{Ca}^{2+}$ concentration $\left(\left[\mathrm{Ca}^{2+}\right] \mathrm{cyt}\right)$, together with $\mathrm{ROS}$ and electrical signals form signaling networks that drive local and systemic defense responses [49]. Toyota and colleagues [50] reported that glutamate (Glu) can act as a DAMP that is sensed by Glu receptor like (GLR) ion channels to trigger an increase in $\left[\mathrm{Ca}^{2+}\right]$ cyt, propagating the defense response to distant organs. In peach leaves, overexpression of GLR (BIN 30.1) and other genes related to $\left[\mathrm{Ca}^{2+}\right] \mathrm{cyt}$ (e.g. various calcium-dependent protein kinases, calmodulin proteins, BIN 30.3 and 17.5) upon Pep treatment suggests that Peps might act as DAMPs and modulate both local and systemic signaling through $\mathrm{Ca}^{2+}$ and perhaps Glu [51].

Plant disease resistance $(R)$ proteins recognize effectors specifically secreted by adapted pathogens to suppress PTI. We found upregulation of several BINs encompassing R proteins: BIN 30.2 (RK with signaling function); BIN 20.1.2 (the two SUBBINs of biotic stress sensing receptors) and BINs 11.9 and 27.3.44 (lipid degradation and chromatin remodeling factors such as rust resistance kinases). Most $\mathrm{R}$ proteins have an LRR motif and many also have a nucleotide binding site (LRR-NBS). Examples of LRR-RLK R proteins that are part of the peach response to Peps are ZAR1, Xa21 and $\mathrm{RCH} 1 . \mathrm{ZAR} 1$ and Xa21 recognize bacterial effectors from Pseudomonas syringae [52] and X. oryzae pv. oryzae (Ax21, [53]) whereas $\mathrm{RCH} 1$ recognizes a fungal effector from Colletotrichum higginsianum [54]. Among the LRR-NBS R proteins induced by PpPeps in peach, four are leaf rust 10 disease-resistance locus receptorlike protein kinases (LRK10L). In wheat, LRK10L proteins recognize effector proteins of the basidiomycete Puccinia striiformis f. sp. tritici Eriks \& Henn, which causes stripe rust, and drives ETI [55]. Noteworthy is that genes belonging to the same BINs were overexpressed in $P$. persica $30 \mathrm{~min}$ to $3 \mathrm{~h}$ after infection with pathogens such as Xap [56]. Persistent exposure to Peps triggers the synthesis of a battery of $\mathrm{R}$ proteins, building up the capacity to establish ETI in response to a variety of virulent pathogens that include bacteria and fungi.

PTI also involves reactions occurring within days, e.g. mainly cell wall remodeling and fortification; and fast synthesis of pathogenesis related proteins (PR) [23, 24] as well. We found that Peps triggered changes in the cell wall related genes (BIN 10) and the biotic stress PR proteins (BIN 20.1.7.1 and 20.7.1.5) 24 and $48 \mathrm{~h}$ after application.

The dynamics of the transcriptomic response of $P$. persica leaves to PpPep1 and PpPep2 were compared to other immune response datasets through DiNAR (Additional files 12 and 13). Similar to P. persica, there is a strong transcriptional response in Arabidopsis shortly after applying a compatible Brassicaceae Pep. This mainly involves upregulation of genes in the same BINs, which in turn are related to the described PTI. Even if data correspond, respectively, to $1 \mathrm{~h}$ and $2 \mathrm{~h}$ PpPep1, PpPep2 and AtPep2 all activate a number of nodes which, in consequence, could be considered candidate indicators of plant responses to Peps. Some examples are the stress related transcription factors ZAT10, ZAT12, WRKY46, LRK10L1.2, the calcium binding proteins CML40 and CML46, the ethylene responsive factors EIN3 and ERF011; the RLKs PBL19 (membrane) and RLK RPP13-like protein 4 (cytoplasmic); and the immune response regulators HSPRO2 (nematode resistance protein), subtilisin-like protease SBT3.3 and F-box protein At1g61340. Ten hours after AtPep2 treatment Arabidopsis virtually had the basal transcriptome, which parallels the peach response to peptides around 1 day after application.

This was in contrast to the dynamics caused by pathogen attack. Pst had a similarly intensive effect on the 
transcriptome of the plant only after $17.5 \mathrm{~h}$. There were 35 and 127 regulated nodes, two and $17.5 \mathrm{~h}$, respectively, after Pst infection. This might be due to progress of the infection, which makes the response of different cells asynchronous and the delay in multiplication of the pathogen that then triggers the response. However, Pst attack and Pep treatment largely affected the same BINs. $64 \%$ nodes regulated by Pst also reacted to Pep, and $84 \%$ nodes regulated by Pep were altered by pathogen attack. This shows that, even if the precise conditions of the compared experiments are different there is an evident parallelism in the transcriptome responses to Pst and AtPep1.

\section{Conclusion}

Here we showed the protective effect of topical application at nanomolar concentrations of either PpPep1 or PpPep2, decreasing the deleterious consequences of massive Xanthomonas arboricola pv. pruni inoculation onto peach plants that were challenged with pathogen concentrations of $10^{8} \mathrm{cfu} / \mathrm{mL}$, i.e. higher than expected in nature. In these extreme conditions, the infection symptoms were reduced by up to $40 \%$.

On characterization of the peach response to topical application of either PpPep1 or PpPep2, in the concentrations giving major protection against Xap, we observed clear PTI activation. This parallels the reported response of Arabidopsis to AtPep1 and confirms that compatible Peps enhance peach basal immunity, so decreasing pathogen effects. The PpPep common transcriptomic response represents $94 \%$ observed variability and this includes PEPR1a, suggesting a role for both PpPep1 and PpPep2 mediated activation of PTI in peach leaves. The similarity of PpPep responses is higher shortly after treatment $(1 \mathrm{~h})$, with some asynchrony at later stages and some variation in the specific regulated genes, always within the same functional categories. The effect of PpPep1 in reducing Xap infection severity peaked at 10-fold lower concentrations than for PpPep2, suggesting that peach leaves have a higher sensitivity to PpPep1 perception and response. The 6\% transcriptome variability in PpPep1 and PpPep2 may be associated with different peptide optimal doses, affinity to the receptor and coreceptors, and persistence in plant leaves.

DiNAR proved to be an intuitive, visual and easy platform to analyze the main results of transcriptomics assays and to compare samples representing different conditions (e.g. species, treatments). The initial selection of the most variable transcripts, custom background network construction and subsequent clustering, proved to be sufficient approach to identify general similarities and major differences between the samples. As an alternative, GSEA uses the full information and is most adequate for detailed comparisons and identification of minor differences in samples.

In this prospective assay, PpPeps was shown to protect peaches from extremely high Xap doses while inducing transcriptomic reprogramming similar to PTI, the natural response to pathogen attack. We found no evidence suggesting that PpPep topical application could rise any food safety concern, so PpPeps seem to be plausible candidate molecules for use in natural and environmentalfriendly agronomic plant protection strategies.

\section{Materials and methods \\ Plant and bacterial material}

Prunus persica var. Big Top (peach) juvenile plants were produced using in vitro technology and grown in individual small pots by a professional grower (Agromillora Iberia S.A., Barcelona, Spain). Prior to experiments they were acclimatized for 2 weeks in a glasshouse $\left(21^{\circ} \mathrm{C}, 16 /\right.$ $8 \mathrm{~h}$ light/dark photoperiod). GF-677, a cross of $P$. persica and $P$. dulcis was used in some experiments, as described in [9].

Xanthomonas arboricola pv. pruni (Xap) strain CFBP 5563 (Collection Française de Bactéries Phytopathogènes, Angers, France) [57] was used to infect peach as described in [9]. A dose of $10^{8} \mathrm{cfu} / \mathrm{mL}$, suspended in sterile water, was prepared immediately before use and the concentration was verified by plate counting. Experimental research was carried out in compliance with relevant national, and international guidelines and legislation, notably Regulation (EU) 2016/2031 of the European Parliament of the Council of 26 October 2016.

\section{In vivo peptide assays}

PpPep1 (EVAASSRVVRQPITTGGGGQIN, full-length mature peptide of MW600836) and PpPep2 (YVQRIT LRAARPEISTGSGAQTN, full-length mature peptide of MW600837) [9] were chemically synthesized (Caslo ApS, Lyngby, Denmark) with purity above $95 \%$ and the identity confirmed by MALDI-TOF. The stock solution was prepared at $1 \mathrm{mM}$ in double-distilled water, and end concentrations of 10, 1, 0.1 and 0 (mock control) $\mu \mathrm{M}$ were prepared prior to use. For treatment with Peps, the five youngest fully expanded leaves of each plant were selected and labelled; and the corresponding Pep was sprayed onto both abaxial and adaxial leaf surfaces. Plants were incubated under standard conditions in the glasshouse. There were three biological replicates of nine plants per treatment.

For RNA-Seq and RT-qPCR analysis, treated leaves were detached 1,24 and $48 \mathrm{~h}$ after peptide treatment, the central vein was cut out and the leaf blades were immediately frozen in liquid nitrogen for subsequent RNA extraction. 
For peptide elicitor activity assays, $650 \mu \mathrm{L}$ of a freshly prepared $10^{8} \mathrm{cfu} / \mathrm{mL}$ Xap suspension was sprayed onto five adult leaves of each plant $24 \mathrm{~h}$ after treatment, with either PpPep1 or PpPep2. The progress of bacterial spot infection was monitored weekly over for three to 4 weeks. For the disease severity index, a 0-to- 6 interval scale was used, corresponding to the level of leaf area affected: $0,1-3,4-8,9-15,16-25,26-45$ and $>45 \%$ (leaf abscission), respectively (Additional file 14, [58]). Disease severity $(S)$ was calculated for each plant according to the equation: $\mathrm{S}=\left[\left(\sum_{n=1}^{N} \mathrm{I}_{\mathrm{n}}\right) / \mathrm{N} \times 6\right] \times 100$, where $I_{n}$ is the severity index for each leaf, $N$ is the number of leaves per plant, and 6 is the maximum severity index value in the scale. Kruskal-Wallis post-hoc pairwise comparisons (IMB SPSS Statistics 25, $p<0.05$ ) were used to analyze the severity. The assays were repeated twice with different batches of plants.

\section{RNA extraction and Illumina sequencing}

RNA was extracted from a $200 \mathrm{mg}$ aliquot of ground leaf sample using a two-step TRIzol-based procedure (Invitrogen Life Technologies, Carlsbad, CA, USA) followed by DNAse I (Ambion, Grand Island, NY, USA) digestion of remaining DNA. For Illumina sequencing, RNA was further purified using RNeasy MinElute Cleanup Kit (Qiagen, Sollentuna, Sweden) according to the manufacturer's instructions. RNA concentration was estimated through absorbance at $260 \mathrm{~nm}$ using a NanoDrop ND1000 spectrophotometer (Nanodrop Technologies, Wilmington, DE, USA).

RNA-Seq was carried out at the National Centre for Genomics Analysis (Barcelona, Spain). Total RNA from Prunus persica was quantified by Qubit ${ }^{\circ}$ RNA BR Assay kit (Thermo Fisher Scientific) and the RNA integrity was estimated by using RNA 6000 Nano Bioanalyzer 2100 Assay (Agilent).

The RNA-Seq libraries were prepared with KAPA Stranded mRNA-Seq Illumina ${ }^{\bullet}$ Platforms Kit (Roche) following the manufacturer's recommendations. Briefly, $500 \mathrm{ng}$ of total RNA was used for the poly-A fraction enrichment with oligo-dT magnetic beads, following the mRNA fragmentation. The strand specificity was achieved during the second strand synthesis performed in the presence of dUTP instead of dTTP. The bluntended double stranded cDNA was 3'adenylated and Illumina platform compatible adaptors with unique dual indexes and unique molecular identifiers (Integrated DNA Technologies) were ligated. The ligation product was enriched with 15 PCR cycles and the final library was validated on an Agilent 2100 Bioanalyzer with the DNA 7500 assay.

The libraries were sequenced on HiSeq 2500 (Illumina) with a read length of $2 \times 76 b p+8 b p+8 b p$ using
TruSeq SBS Kit v4 (Illumina). Image analysis, base calling and quality scoring of the run were processed using the manufacturer's software Real Time Analysis (RTA 1.18.66.3).

\section{Bioinformatics analysis}

RNA-Seq reads were mapped to the Prunus persica NCBIv2 reference genome using the STAR v2.5.3a software with ENCODE parameters from long RNA [59]. Gene quantification was performed with RSEM version 1.3.0 with default parameters using the Prunus persica NCBIv2.38 annotation version. Differential expression analysis was performed with $\mathrm{R}$ package DESeq2 version 1.20.0 [60] with default parameters. Genes were considered significant with $\mathrm{FDR}<0.01$ and $|\log 2 \mathrm{FC}|>1$.

The annotation of $P$. persica genes based on their corresponding orthologues in Arabidopsis thaliana was performed using the Genome Database for Rosaceae [61]. Overlapping DEG in response to PpPep1 and PpPep2 were represented using the BioVenn application [62]. Agglomerative Hierarchical Clustering (Euclidean distance, ward. D agglomeration method) of 2542 selected genes (log2FC along 6 comparisons) was conducted in R [63] using gplots library [64].

Gene set enrichment analysis was carried out with GSEA v4.0.1 [65]. RNA-Seq ranked gene list was input to GSEA [30] and the settings applied were: 'gene set permutation' as statistical significance of the enrichment score, signal-to-noise ratio as the ranking metric, settling 1000 permutations per test and excluding sets not within 15-500. The resulting pathways were selected using a FDR $Q$ value threshold $<0.01$ and ranked using Normalized Enrichment Score (NES).

Transcriptomic time-point dynamic changes were visualized using DiNAR [66]. A custom background knowledge network was constructed using orthologue gene information (PLAZA v4.0, [67]) based translation of A. thaliana network [31] to Prunus persica network and further clustered using the multi-level modularity optimization algorithm using DiNARs' subapps. Peach gene IDs within one orthologue group were prioritized based on their expression using the accompanying DiNARs script for ID prioritization. To facilitate interpretation of the DiNAR output, we manually organized the coordinates of the background network nodes (Cytoscape v3.7.2, [68] on the basis of their functional category prescribed BINs as defined by the MapMan resource for gene functional annotations [69, 70]. Nodes associated to the same BIN were aligned in the neighborhoods, and the most relevant BINs encompassing the nodes with the highest regulation were displayed in the $P$. persica Pep background network. Additional files 15 and 16 compiles the input data of this network (also available 
on https://github.com/NIB-SI/DiNAR/tree/master/ PEPN).

\section{RT-qPCR analysis}

Reverse transcription and real-time PCR (RT-qPCR) was performed to validate the RNA-Seq results and to conduct the additional gene expression analysis. For specific qPCR optimization, the selected genes were PCR-amplified from cDNA, synthesized from untreated leaf samples, and PCR products were cloned using the pSpark DNA cloning system (Canvax, Córdoba, Spain). The reaction conditions were as follows: $2 \mathrm{~min}$ at $94{ }^{\circ} \mathrm{C} ; 10$ cycles of $15 \mathrm{~s}$ at $94{ }^{\circ} \mathrm{C}$, $30 \mathrm{~s}$ at the appropriate annealing temperature (Additional file 17) and $45 \mathrm{~s}$ at $72{ }^{\circ} \mathrm{C} ; 20$ cycles of $15 \mathrm{~s}$ at $94{ }^{\circ} \mathrm{C}$, $30 \mathrm{~s}$ at the same annealing temperature and $45 \mathrm{~s}$, plus an additional $5 \mathrm{~s}$ for each successive cycle at $72^{\circ} \mathrm{C}$; and a final extension of $7 \mathrm{~min}$ at $72^{\circ} \mathrm{C}$.

cDNA was synthesized from RNA samples using High Capacity cDNA Reverse Transcription Kits (Thermo Fisher Scientific Inc.). The qPCRs were performed in a final volume of $20 \mu \mathrm{L}$, containing 1X SYBR Green PCR Master Mix (Thermo Fisher Scientific Inc.), the appropriate concentrations of primers (Merck KGaA, Darmstadt, Germany) (Additional file 17) and $1 \mu \mathrm{L}$ cDNA. The reaction conditions were as follows: $10 \mathrm{~min}$ at $95^{\circ} \mathrm{C}$ for initial denaturation; 50 cycles of $15 \mathrm{~s}$ at $95 \mathrm{C}$ and 1 min at $60^{\circ} \mathrm{C}$; and a final melting curve program of 60 $95^{\circ} \mathrm{C}$ with a heating rate of $0.5^{\circ} \mathrm{C} / \mathrm{s}$. Melting curve analyzes produced single peaks, with no primer-dimer peaks or artefacts, indicating the reactions were specific. Average expression stability (M-value) of two described reference genes for P. persica-TEF2 and UBQ- $[9,71]$ were determined by the GeNorm v3.4 algorithm [72]. Both M-values were $<0.5$ and TEF2 was used for normalization in rear assays. The comparative $\mathrm{Ct}(\Delta \Delta \mathrm{Ct})$ method and $\mathrm{T}$-test or the corresponding non-parametric analysis were executed with Genex v.4.3.1 software for differential expression analysis, using adjusted $p$ value of $1 \%$ as threshold.

\section{Abbreviations}

Pep: Plant elicitor peptide; PROPEP: Pep precursor; PEPR: Pep receptor; LRR: Leucine rich repeat domain; PTI: Pattern-triggered immunity; DiNAR: Differential Network Analysis in R; PEPN: P. persica Pep background network

\section{Supplementary Information}

The online version contains supplementary material available at https://doi. org/10.1186/s12864-021-07571-9.

Additional file 1. Quality control and mapping statistics of Prunus persica RNA-Seq analyses using Illumina.

Additional file 2. RNA-Seq results were validated by RT-qPCR. Identification and GO classification of the 19 selected genes and log2FC values obtained for the same samples through both techniques. Cell colors distinguish statistically significant regulated genes (blue, down-regulated; red, up-regulated) from non-significant, shown in white (adj. $p<0.01$ $|\log 2 \mathrm{FC}|>1.0$ for RNA-Seq; adj. $p<0.05$ for RT-qPCR). Graph on the right shows simple linear regression between log2FC values using the two techniques with correlation coefficient of 0.92 .

Additional file 3. Interactive principal component analysis (PCA) of regularized-logarithm normalized expression data from the 500 genes showing the highest variance (DESeq2 1.20.0 package [60]) conducted in R [63] using scatter plot 3 d library [73]. Three principal components, PC1, PC2 and PC3, with Eigenvalues above 1 explained 83.84\%, 7.04\% and $2.81 \%$ of the overall variability, respectively. The peptide treatments are shown in different colors: tan, time zero (t0); turquoise, 1 h PpPep1 (P1t1) light green, 1 h PpPep2 (P2t1); blue, 24 h PpPep1 (P1t24); pink, 24 h PpPep2 (P2t24); orange, 48 h PpPep1 (P1t48); yellow, 48 h PpPep2 (P2t48). Three biological replicates per sample are shown.

Additional file 4. RT-qPCR analysis of the same 19 genes used to validate RNA-Seq results (where the expression is regulated by application of PpPeps, Additional file 2), in mock samples taken at the 0, 1, 24 and $48 \mathrm{~h}$ time-points ( $p>0.01$, IBM SPSS statistics 25).

Additional file 5. Table of number and percentages of differentially expressed genes (DEG) in response to PpPep1 and PpPep2 at 1, 24 and $48 \mathrm{~h}$ after peptide application, with adjusted $p$-value cut-off 0.01 . Contrasts are defined in the first column, where $t$ stands for time, $\mathrm{P}$ for Pep, '_' separates the conditions and $\cap$ for intersecting data between comparisons. DEG percentages are calculated according to the total number of genes in the $P$. persica genome.

Additional file 6. Venn diagrams representing overlapping differentially expressed genes in response to PpPep1 (left panel) and PpPep2 (middle panel), as well as genes commonly regulated in both treatments (right panel). 1 h: 1 h vs. control; 24 h: 24 h vs. 1 h; 48 h: 48 h vs. 24 h; n: intersection i.e. common DEGs between comparisons; red numbers: upregulated genes; blue numbers: downregulated genes.

Additional file 7. Interactive heat map showing relative expression levels of genes that are regulated in at least one comparison (adj. $p<$ 0.01, $|\log 2 \mathrm{FC}|>1.0)$ : P1t1 vs. t0, P2t1 vs. t0, P1t24 vs. t1, P2t24 vs. t1, P1t48 vs. t24, and P2t48 vs. t24. P1: treatment with PpPep1; P2: treatment with PpPep2; t stands for time and is given in hours; and the dash corresponds to vs.. The rainbow color scale represents highly positive to highly negative log2FC (7 to -7), white corresponding to 0 . Gene codes are displayed on the left. Top right menu helps surfing the plot, zooming interesting areas or identifying gene codes for each expression value.

Additional file 8. Interpretation of the transcriptomic response of $P$. persica leaves to treatment with PpPeps. Gene set enrichment analysis using GSEA and $p<0.01$ in time and peptide comparisons (left and right, respectively). In time comparison, red indicates upregulation and blue downregulation of the genes contributing to each BIN in the first vs. the second time condition in the upper row. In peptide comparison, orange and green indicate overexpression in PpPep1 and PpPep2, respectively, of the genes contributing to each bin. Bright red, blue, orange or green indicate statistically significant enrichment. Light colors indicate the absence of statistically significant enrichment. Size indicates the number of genes in the gene set after filtering out those not in the expression dataset.

Additional file 9. Detailed data of gene set enrichment analysis using GSEA and adjusted $p<0.01$ in time comparisons. For every statistically enriched bin, all genes contributing to the enrichment are listed, as well as expression, description traits and additional GSEA ranking information.

Additional file 10. Dynamic visualization of Prunus persica response to PpPep1 from RNA-Seq experimental data on DiNAR application, P. persica Pep network (PEPN). Only differentially expressed genes are visualized (adj. $p<0.01,|\log 2 \mathrm{FC}|>1.0)$. Dynamic changes in gene expression after 1, 24 and 48 hours vs. non-treated samples are shown. Node colors correspond to gene regulation (red, upregulated and blue downregulated). Node sizes correspond to absolute log2FC values and are related to the maximum value in each time condition. Time points scale is at the bottom.

Additional file 11. Dynamic visualization of Prunus persica response to PpPep2 from RNA-Seq experimental data on DiNAR application, P. persica 
Pep network (PEPN). Only differentially expressed genes are visualized (adj. $p<0.01,|\log 2 \mathrm{FC}|>1.0$ ). Dynamic changes in gene expression after 1 , 24 and 48 hours vs. non-treated samples are shown. Node colors correspond to gene regulation (red, upregulated and blue downregulated). Node sizes correspond to absolute $\log 2 \mathrm{FC}$ values and are related to the maximum value in each time condition. Time points scale is at the bottom.

Additional file 12. Dynamic visualization of $A$. thaliana response to AtPep2 from microarray experimental data [22] on DiNAR application, P. persica Pep network (PEPN). Only differentially expressed genes are visualized (adj. $p<0.05,|\log 2 \mathrm{FC}|>1.0$ ). Dynamic changes in gene expression after 2 and 10 hours vs. on-treated samples are shown. Node colors correspond to gene regulation (red, upregulated and blue downregulated). Node sizes correspond to absolute $\log 2 \mathrm{FC}$ values and are related to the maximum value in each time condition. Time points scale is at the bottom

Additional file 13. Dynamic visualization of $A$. thaliana response to Pseudomonas syringae pv. tomato DC3000 RNA-Seq experimental data $[66,74]$ on DiNAR application, P. persica Pep network (PEPN). Only differentially expressed genes are visualized (adj. $p<0.05,|\log 2 \mathrm{FC}|>1.0$ ). Dynamic changes in gene expression following $0,2,3,4,6,7,8,10,11,12$, 14,16 and 17.5 hours vs. mock samples are shown. Node colors correspond to gene regulation (red, upregulated and blue downregulated). Node sizes correspond to absolute $\log 2 \mathrm{FC}$ values and are related to the maximum value in each time condition. Time points scale is at the bottom.

Additional file 14. Bacterial spot disease severity was determined by assessing Xap infected leaves using a 0-to-6 interval scale according to percent leaf area affected [58]. Disease severity (S) was calculated for each plant according to the indicated formula, where $I n$ is the severity index for each leaf, $N$ is the number of leaves per plant, and $\sigma$ is the maximum severity index value in the scale.

Additional file 15. Nodes and edges input information needed for visualization of $P$. persica Pep DiNAR network (PEPN) on DiNAR. These databases were built using peach to $A$. thaliana translation based on orthologue gene information.

Additional file 16. Edges input information needed for visualization of P. persica Pep DiNAR network (PEPN) on DiNAR. These databases were built using peach to $A$. thaliana translation based on orthologue gene information.

Additional file 17. Primers used in RT-qPCR assays and their properties, including those targeting 19 genes selected for RNA-Seq validation and two described $P$. persica reference genes (TEF2 and UBQ, $[9,71]$ ).

\section{Acknowledgements}

We thank Dr. S. Burgess for English correction of the manuscript, Agromillora Iberia S.A. for the provision of the plant material.

\section{Authors' contributions}

MP and AN conceived and supervised the study, LF carried out the experiments and participated in the analysis of the data. AEC carried out the analysis of transcriptomics. KG, MZ and ZR designed and carried out network and expression data analysis. All authors supervised and approved the final manuscript.

\section{Funding}

This work was supported by the Spanish MINECO (Grant AGL2017-85121-R), funded by Ministerio de Economía, Industria y Competividad, Slovene Research Agency (grants P4-0165, J4-1777, J4-9302 and Z7-1888), L. F received fellowships from Generalitat de Catalunya (2017FI_B_00435) and AEC was funded by ISCIII /MINECO (PT17/0009/0019) and co-funded by FEDE $R$. The funding bodies did not contribute to the design of the study or collection, analysis and interpretation of data and writing the manuscript.

\section{Availability of data and materials}

The datasets supporting the conclusions of this article are publicly available in the Gene Expression Omnibus (GEO) repository, record GSE161802 (https://www.ncbi.nlm.nih.gov/geo/query/acc.cgi?acc=GSE161802).

\section{Declarations}

\section{Ethics approval and consent to participate}

Experimental research has been carried out in compliance with relevant national, and international guidelines and legislation, notably Regulation (EU) 2016/2031 of the European Parliament of the Council of 26 October 2016.

\section{Consent for publication}

Not applicable.

\section{Competing interests}

The authors declare that they have no competing interests.

\section{Author details}

${ }^{1}$ Institute for Agricultural and Food Technology, Universitat de Girona, Campus Montilivi (EPS-1), 17003 Girona, Spain. ${ }^{2}$ Department of Biotechnology and Systems Biology, National Institute of Biology, Večna pot 111, 1000 Ljubljana, Slovenia. ${ }^{3}$ CNAG-CRG, Centre for Genomic Regulation, Barcelona Institute of Science and Technology, 08028 Barcelona, Spain. ${ }^{4}$ Universitat Pompeu Fabra (UPF), Barcelona, Spain.

Received: 16 December 2020 Accepted: 23 March 2021 Published online: 18 May 2021

\section{References}

1. Huffaker A, Pearce G, Ryan CA. An endogenous peptide signal in Arabidopsis activates components of the innate immune response. Proc Natl Acad Sci U S A. 2006;103(26):10098-103. https://doi.org/10.1073/pnas. 0603727103.

2. Bartels S, Lori M, Mbengue M, Van Verk M, Klauser D, Hander T, et al. The family of peps and their precursors in arabidopsis: differential expression and localization but similar induction of pattern-triggered immune responses. J Exp Bot. 2013;64(17):5309-21. https://doi.org/10.1 093/jxb/ert330.

3. Lori M, Van Verk MC, Hander T, Schatowitz $H$, Klauser D, Flury P, et al. Evolutionary divergence of the plant elicitor peptides (peps) and their receptors: interfamily incompatibility of perception but compatibility of downstream signalling. J Exp Bot. 2015;66(17):5315-25. https://doi.org/10.1 093/jxb/erv236.

4. Tang J, Han Z, Sun Y, Zhang H, Gong X, Chai J. Structural basis for recognition of an endogenous peptide by the plant receptor kinase PEPR1. Cell Res. 2015;25(1):110-20. https://doi.org/10.1038/cr.2014.161.

5. Albert M. Peptides as triggers of plant defence. J Exp Bot. 2013;64(17):526979. https://doi.org/10.1093/jxb/ert275.

6. Yamaguchi $Y$, Huffaker A. Endogenous peptide elicitors in higher plants. Curr Opin Plant Biol. 2011;14(4):351-7. https://doi.org/10.1016/j.pbi.2011. 05.001.

7. Huffaker A, Pearce G, Veyrat N, Erb M, Turlings TCJ, Sartor R, et al. Plant elicitor peptides are conserved signals regulating direct and indirect antiherbivore defense. Proc Natl Acad Sci U S A. 2013;110(14):5707-12. https://doi.org/10.1073/pnas.1214668110.

8. Trivilin AP, Hartke S, Moraes MG. Components of different signalling pathways regulated by a new orthologue of AtPROPEP1 in tomato following infection by pathogens. Plant Pathol. 2014;63(5):1110-8. https:// doi.org/10.1111/ppa.12190.

9. Ruiz C, Nadal A, Montesinos E, Pla M. Novel Rosaceae plant elicitor peptides as sustainable tools to control Xanthomonas arboricola pv. Pruni in Prunus spp. Mol Plant Pathol. 2017;19(2):418-31. https://doi.org/10.1111/mpp.12534.

10. Ruiz C, Nadal A, Foix L, Montesinos L, Montesinos E, Pla M. Diversity of plant defense elicitor peptides within the Rosaceae. BMC Genet. 2018;19:1-12.

11. Yamaguchi $Y$, Pearce $G$, Ryan $C A$. The cell surface leucine-rich repeat receptor for AtPep1, an endogenous peptide elicitor in Arabidopsis, is functional in transgenic tobacco cells. Proc Natl Acad Sci U S A. 2006; 103(26):10104-9. https://doi.org/10.1073/pnas.0603729103.

12. Yamaguchi $Y$, Huffaker A, Bryan AC, Tax FE, Ryan CA. PEPR2 is a second receptor for the Pep1 and Pep2 peptides and contributes to defense responses in Arabidopsis. Plant Cell. 2010;22(2):508-22. https://doi.org/10.11 05/tpc.109.068874.

13. Klauser D, Flury P, Boller T, Bartels S. Several MAMPs, including chitin fragments, enhance AtPep-triggered oxidative burst independently of 
wounding. Plant Signal Behav. 2013;8(9):10-2. https://doi.org/10.4161/ psb.25346.

14. Krol E, Mentzel T, Chinchilla D, Boller T, Felix G, Kemmerling B, et al. Perception of the Arabidopsis danger signal peptide 1 involves the pattern recognition receptor AtPEPR1 and its close homologue AtPEPR2. J Bio Chem. 2010;285(18):13471-9. https://doi.org/10.1074/jbc.M109.097394.

15. Lu D, Wu S, Gao X, Zhang Y, Shan L, He P. A receptor-like cytoplasmic kinase, BIK1, associates with a flagellin receptor complex to initiate plant innate immunity. Proc Natl Acad Sci U S A. 2010;107(1):496-501. https://doi. org/10.1073/pnas.0909705107.

16. Hander T, Fernández-Fernández ÁD, Kumpf RP, Willems P, Schatowitz H, Rombaut $\mathrm{D}$, et al. Damage on plants activates $\mathrm{Ca} 2+-$ dependent metacaspases for release of immunomodulatory peptides. Science. 2019;363:6433.

17. Ortiz-Morea FA, Savatin DV, Dejonghe W, Kumar R, Luo Y, Adamowski $\mathrm{M}$, et al. Danger-associated peptide signaling in Arabidopsis requires clathrin. Proc Natl Acad Sci. 2016;113(39):11028-33. https://doi.org/10.1 073/pnas.1605588113.

18. Qi Z, Verma R, Gehring C, Yamaguchi Y, Zhao Y, Ryan CA, et al. Ca2+ signaling by plant Arabidopsis thaliana Pep peptides depends on AtPepR1, a receptor with guanylyl cyclase activity, and cGMP-activated Ca2+ channels. Proc Natl Acad Sci U S A. 2010:107:21193-8.

19. Bigeard J, Colcombet J, Hirt H. Signaling mechanisms in patterntriggered immunity (PTI). Mol Plant. 2015;8(4):521-39. https://doi.org/1 0.1016/j.molp.2014.12.022

20. Cui F, Sun W, Kong X. RLCKs bridge plant immune receptors and MAPK cascades. Trends Plant Sci. 2018;23(12):1039-41. https://doi.org/10.1016/j.tpla nts.2018.10.002.

21. Ryan CA, Huffaker A, Yamaguchi Y. New insights into innate immunity in Arabidopsis. Cell Microbiol. 2007;9(8):1902-8. https://doi.org/10.1111/j.14625822.2007.00991.x.

22. Ross A, Yamada K, Hiruma K, Yamashita-Yamada M, Lu X, Takano Y, et al. The Arabidopsis PEPR pathway couples local and systemic plant immunity. EMBO J. 2014;33(1):62-75. https://doi.org/10.1002/embj.201284303.

23. Boller T, Felix G. A renaissance of elicitors: perception of microbe-associated molecular patterns and danger signals by pattern-recognition receptors. Annu Rev Plant Biol. 2009;60(1):379-406. https://doi.org/10.1146/annurev.a rplant.57.032905.105346.

24. Segonzac C, Zipfel C. Activation of plant pattern-recognition receptors by bacteria. Curr Opin Microbiol. 2011;14(1):54-61. https://doi.org/10.1016/j. mib.2010.12.005.

25. Safaeizadeh M, Boller T. Differential and tissue-specific activation pattern of the AtPROPEP and AtPEPR genes in response to biotic and abiotic stress in Arabidopsis thaliana. Plant Signal Behav. 2019;14(5):1-17. https://doi.org/10.1 080/15592324.2019.1590094.

26. Bartels S, Boller T. Quo vadis, pep? Plant elicitor peptides at the crossroads of immunity, stress, and development. J Exp Bot. 2015;66(17):5183-93. https://doi.org/10.1093/jxb/erv180.

27. Gully K, Hander T, Boller T, Bartels S. Perception of Arabidopsis AtPep peptides, but not bacterial elicitors, accelerates starvation-induced senescence. Front Plant Sci. 2015:1-10. https://doi.org/10.3389/fpls.2015.00014.

28. FAOSTAT. http://www.fao.org/faostat/en/\#data/QC. Accessed 21 Sept 2020

29. Esteve-Codina A. RNA-Seq Data Analysis, Applications and Challenges. 1st ed: Elsevier B.V.; 2018. https://doi.org/10.1016/bs.coac.2018.06.001.

30. Reimand J, Isserlin R, Voisin V, Kucera M, Tannus-Lopes C, Rostamianfar A, Wadi L, Meyer M, Wong J, Xu C, Merico D, Bader GD Pathway enrichment analysis and visualization of omics data using g:profiler, GSEA, Cytoscape and EnrichmentMap. Nat Protoc 2019;14:482-517. https://doi.org/10.1038/ s41596-018-0103-9.

31. Ramšak Ž, Coll A, Stare T, Tzfadia O, Baebler Š, Van de Peer Y, et al. Network modeling unravels mechanisms of crosstalk between ethylene and salicylate signaling in potato. Plant Physiol. 2018;178:488-99.

32. Preston GM. Pseudomonas syringae pv. Tomato: the right pathogen, of the right plant, at the right time. Mol Plant Pathol. 2000;1 (5):263-75. https://doi. org/10.1046/j.1364-3703.2000.00036.x.

33. Klauser D, Desurmont GA, Glauser $G$, Vallat A, Flury P, Boller T, et al. The Arabidopsis pep-PEPR system is induced by herbivore feeding and contributes to JA-mediated plant defence against herbivory. J Exp Bot. 2015;66(17):5327-36. https://doi.org/10.1093/jxb/erv250

34. Liu Z, WU Y, Yang F, Zhang Y, Chen S, Xie Q, et al. BIK1 interacts with PEPRs to mediate ethylene-induced immunity. Proc Natl Acad Sci U S A. 2013; 110(15):6205-10. https://doi.org/10.1073/pnas.1215543110.
35. Veronese P, Nakagami H, Bluhm B, AbuQamar S, Chen X, Salmeron J, et al. The membrane-anchored BOTRYTIS-INDUCED KINASE1 plays distinct roles in Arabidopsis resistance to necrotrophic and biotrophic pathogens. Plant Cell. 2006;18(1):257-73. https://doi.org/10.1105/tpc.105.035576.

36. Zhang J, Li W, Xiang T, Liu Z, Laluk K, Ding X, et al. Receptor-like cytoplasmic kinases integrate signaling from multiple plant immune receptors and are targeted by a Pseudomonas syringae effector. Cell Host Microbe. 2010;7(4):290-301. https://doi.org/10.1016/j.chom.2010.03.007.

37. Li L, Li M, Yu L, Zhou Z, Liang X, Liu Z, et al. The FLS2-associated kinase BIK1 directly phosphorylates the NADPH oxidase RbohD to control plant immunity. Cell Host Microbe. 2014;15(3):329-38. https://doi.org/10.1016/j. chom.2014.02.009.

38. Orosa B, Yates G, Verma V, Srivastava AK, Srivastava M, Campanaro A, et al. SUMO conjugation to the pattern recognition receptor FLS2 triggers intracellular signalling in plant innate immunity. Nat Commun. 2018;9(1):112. https://doi.org/10.1038/s41467-018-07696-8.

39. Garner CM, Kim SH, Spears BJ, Gassmann W. Express yourself: transcriptional regulation of plant innate immunity. Semin Cell Dev Biol. 2016;56:150-62. https://doi.org/10.1016/j.semcdb.2016.05.002.

40. Logemann E, Birkenbihl RP, Rawat V, Schneeberger K, Schmelzer E, Somssich IE. Functional dissection of the PROPEP2 and PROPEP3 promoters reveals the importance of WRKY factors in mediating microbe-associated molecular pattern-induced expression. New Phytol. 2013;198(4):1165-77. https://doi.org/10.1111/nph.12233.

41. Mishina TE, Zeier J. Pathogen-associated molecular pattern recognition rather than development of tissue necrosis contributes to bacterial induction of systemic acquired resistance in Arabidopsis. Plant J. 2007;50(3): 500-13. https://doi.org/10.1111/j.1365-313X.2007.03067.X.

42. Liu Y, Zhang S. Phosphorylation of 1-aminocyclopropane-1-carboxylic acid synthase by MPK6, a stress-responsive mitogen-activated protein kinase, induces ethylene biosynthesis in arabidopsis. Plant Cell. 2004;16(12):338699. https://doi.org/10.1105/tpc.104.026609.

43. Qin YM, Hu CY, Pang Y, Kastaniotis AJ, Hiltunen JK, Zhu YX. Saturated verylong-chain fatty acids promote cotton fiber and Arabidopsis cell elongation by activating ethylene biosynthesis. Plant Cell. 2007;19:3692-704.

44. Huang PY, Catinot J, Zimmerli L. Ethylene response factors in Arabidopsis immunity. J Exp Bot. 2016;67(5):1231-41. https://doi.org/10.1093/jxb/erv518.

45. Xin XF, Nomura K, Ding X, Chen X, Wang K, Aung K, et al. Pseudomonas syringae effector avirulence protein $E$ localizes to the host plasma membrane and down-regulates the expression of the NONRACE-SPECIFIC DISEASE RESISTANCE1/HARPIN-INDUCED1-LIKE13 gene required for antibacterial immunity in Arabidopsis. Plant Physiol. 2015;169(1):793-802. https://doi.org/10.1104/pp.15.00547.

46. Wu Y, Zhang D, Chu JY, Boyle P, Wang Y, Brindle ID, et al. The Arabidopsis NPR1 protein is a receptor for the plant defense hormone salicylic acid. Cell Rep. 2012; (6):639-47. https://doi.org/10.1016/j.celrep.2012.05.008.

47. Mauch-Mani B, Mauch F. The role of abscisic acid in plant-pathogen interactions. Curr Opin Plant Biol. 2005;8(4):409-14. https://doi.org/10.1016/j. pbi.2005.05.015.

48. Zhang Y, Li X. Salicylic acid: biosynthesis, perception, and contributions to plant immunity. Curr Opin Plant Biol. 2019;50:29-36. https://doi.org/10.1016/ j.pbi.2019.02.004.

49. Choi WG, Miller G, Wallace I, Harper J, Mittler R, Gilroy S. Orchestrating rapid long-distance signaling in plants with $\mathrm{Ca} 2+$, ROS and electrical signals. Plant J. 2017;90(4):698-707. https://doi.org/10.1111/tpj.13492.

50. Toyota M, Spencer D, Sawai-toyota S, Jiaqi W, Zhang T. Glutamate triggers long-distance, calcium-based plant defense signaling. Science. 2018;361: $1112-5$.

51. Qiu XM, Sun YY, Ye XY, Li ZG. Signaling Role of Glutamate in Plants. Front Plant Sci. 2020;10:1-11.

52. Lewis JD, Wu R, Guttman DS, Desveaux D. Allele-specific virulence attenuation of the Pseudomonas syringae HopZ1a type III effector via the Arabidopsis ZAR1 resistance protein. PLoS Genet. 2010;6(4):e1000894. https://doi.org/10.1371/journal.pgen.1000894.

53. Park CJ, Ronald PC. Cleavage and nuclear localization of the rice XA21 immune receptor. Nat Commun. 2012;3(1):920. https://doi.org/10.1038/ ncomms1932.

54. Narusaka Y, Narusaka M, Park P, Kubo Y, Hirayama T, Seki M, et al. RCH1, a locus in Arabidopsis that confers resistance to the hemibiotrophic fungal pathogen Colletotrichum higginsianum. Mol Plant-Microbe Interact. 2004; 17(7):749-62. https://doi.org/10.1094/MPMI.2004.17.7.749. 
55. Liu W, Frick M, Huel R, Nykiforuk CL, Wang X, Gaudet DA, et al. The stripe rust resistance gene Yr10 encodes an evolutionary-conserved and unique CC-NBS-LRR sequence in wheat. Mol Plant. 2014;7(12):1740-55. https://doi. org $/ 10.1093 / \mathrm{mp} / \mathrm{ssu} 112$

56. Gervasi F, Ferrante P, Dettori MT, Scortichini M, Verde I. Transcriptome reprogramming of resistant and susceptible peach genotypes during Xanthomonas arboricola pv. Pruni early leaf infection. PLoS One. 2018; 13:1-21.

57. Boudon S, Manceau C, Nottéghem J-L. Structure and origin of Xanthomonas arboricola pv. Pruni populations causing bacterial spot of stone fruit trees in Western Europe. Phytopathology. 2005;95(9):1081-8. https://doi.org/10.1094/PHYTO-95-1081.

58. Bardsley SJ, Ngugi HK. Reliability and accuracy of visual methods to quantify severity of foliar bacterial spot symptoms on peach and nectarine. Plant Pathol. 2013;62(2):460-74. https://doi.org/10.1111/j.1365-3059.2012.02651.x

59. Dobin A, Davis CA, Schlesinger F, Drenkow J, Zaleski C, Jha S, et al. STAR: Ultrafast universal RNA-seq aligner. Bioinformatics. 2013;29:15-21.

60. Love Ml, Huber W, Anders S. Moderated estimation of fold change and dispersion for RNA-seq data with DESeq2. Genome Biol. 2014;15(12):550 https://doi.org/10.1186/s13059-014-0550-8

61. Jung $S$, Lee T, Cheng CH, Buble K, Zheng P, Yu J, et al. 15 years of GDR: new data and functionality in the genome database for Rosaceae. Nucleic Acids Res. 2019;47(D1):D1137-45. https://doi.org/10.1093/nar/gky1000.

62. Hulsen T, de Vlieg J, Alkema W. BioVenn - A web application for the comparison and visualization of biological lists using area-proportional Venn diagrams. BMC Genomics. 2008;9:1-6.

63. R Core Team. R: a Language and Environment for Statistical Computing. Vienna: R Found Stat Comput; 2019. http://www.r-project.org.

64. Murtagh F, Legendre P. Ward's hierarchical agglomerative clustering method: which algorithms implement Ward's criterion? J Classif. 2014;31: 274-95.

65. Subramanian A, Tamayo P, Mootha VK, Mukherjee S, Ebert BL, Gillette MA, et al. Gene set enrichment analysis: a knowledge-based approach for interpreting genome-wide expression profiles. Proc Natl Acad Sci U S A. 2005;102(43):15545-50. https://doi.org/10.1073/pnas.0506580102.

66. Zagorščak M, Blejec A, Ramšak Ž, Petek M, Stare T, Gruden K. DiNAR: revealing hidden patterns of plant signalling dynamics using differential network analysis in R. Plant Methods. 2018;14(1):1-9. https://doi.org/10.11 86/s13007-018-0345-0.

67. Van Bel M, Diels T, Vancaester E, Kreft L, Botzki A, Van De Peer Y, et al. PLAZA 4.0: An integrative resource for functional, evolutionary and comparative plant genomics. Nucleic Acids Res. 2018:46:D1190-6.

68. Shannon P, Markiel A, Ozier O, Baliga NS, Wang JT, Ramage D, et al. Cytoscape: A software Environment for integrated models of biomolecular interaction networks. Genome Res. 2003;13:2498-504.

69. Thimm O, Bläsing O, Gibon Y, Nagel A, Meyer S, Krüger P, et al. MAPMAN: A user-driven tool to display genomics data sets onto diagrams of metabolic pathways and other biological processes. Plant J. 2004;37:914-39.

70. Ramšak Ž, Baebler $\breve{S}$, Rotter A, Korbar M, Mozetič I, Usadel B, et al. GoMapMan: Integration, consolidation and visualization of plant gene annotations within the MapMan ontology. Nucleic Acids Res. 2014;42: D1167-75.

71. Tong Z, Gao Z, Wang F, Zhou J, Zhang Z. Selection of reliable reference genes for gene expression studies in peach using real-time PCR. BMC Mol Biol. 2009;10:1-3.

72. Vandesompele J, De Preter K, Pattyn F, Poppe B, Van Roy N, De Paepe $A$, et al. Accurate normalization of real-time quantitative RT-PCR data by geometric averaging of multiple internal control genes. Genome Biol. 2002;3:1-2.

73. Ligges U, Mächler M. Scatterplot3d - An R package for visualizing multivariate data. J Stat Softw. 2003:8(11). https://doi.org/10.18637/jss.V008.i11.

74. Lewis LA, Polanski K, de Torres-Zabala M, Jayaraman S, Bowden L, Moore J, et al. Transcriptional dynamics driving MAMP-triggered immunity and pathogen effector-mediated immunosuppression in Arabidopsis leaves following infection with Pseudomonas syringae pv tomato DC3000. Plant Cell. 2015;27(11):3038-64. https://doi.org/10.1105/tpc.15.00471.

\section{Publisher's Note}

Springer Nature remains neutral with regard to jurisdictional claims in published maps and institutional affiliations.

\section{Ready to submit your research? Choose BMC and benefit from:}

- fast, convenient online submission

- thorough peer review by experienced researchers in your field

- rapid publication on acceptance

- support for research data, including large and complex data types

- gold Open Access which fosters wider collaboration and increased citations

- maximum visibility for your research: over $100 \mathrm{M}$ website views per year

At $\mathrm{BMC}$, research is always in progress.

Learn more biomedcentral.com/submissions 